\title{
E-H Bond Activation and Insertion Processes in the Reactions of the Unsaturated Hydride $\left[\mathrm{W}_{2} \mathrm{Cp}_{2}(\mu-\mathrm{H})(\mu-\right.$ $\left.\left.\mathbf{P P h}_{2}\right)(\mathrm{NO})_{2}\right]$
}

\author{
M. Angeles Alvarez, M. Esther García, Daniel García-Vivó,* Miguel A. Ruiz,* and \\ Adrián Toyos.
}

Departamento de Química Orgánica e Inorgánica/IUQOEM, Universidad de Oviedo, E-33071 Oviedo, Spain.

\begin{abstract}
The reactions of the title complex (1) with different $p$-block element (E) molecules was examined. Compound 1 reacted with $\mathrm{BH}_{3}$. THF at room temperature to give the trihydride $\left[\mathrm{W}_{2} \mathrm{Cp}_{2}(\mu-\mathrm{H}) \mathrm{H}_{2}\left(\mu-\mathrm{PPh}_{2}\right)(\mathrm{NO})_{2}\right]$, which formally results from hydrogenation of $\mathbf{1}$, a reaction actually not taking place when using neat dihydrogen. Clean $\mathrm{E}-\mathrm{H}$ bond oxidative addition, however, took place when reacting 1 with $\mathrm{HSnPh}_{3}$, to give the related dihydride stannyl derivative $\left[\mathrm{W}_{2} \mathrm{Cp}_{2}(\mu-\mathrm{H}) \mathrm{H}\left(\mu-\mathrm{PPh}_{2}\right)(\mathrm{NO})_{2}\left(\mathrm{SnPh}_{3}\right)\right]$. In contrast, the reaction of 1 with $\mathrm{HSPh}$ involved $\mathrm{H}_{2}$ elimination to give the thiolate-bridged complex $\left[\mathrm{W}_{2} \mathrm{Cp}_{2}(\mu-\mathrm{SPh})\left(\mu-\mathrm{PPh}_{2}\right)(\mathrm{NO})_{2}\right]$, while that with $(p$-tol $) \mathrm{C}(\mathrm{O}) \mathrm{H}$ resulted in insertion of the aldehyde to yield the related alkoxide complex $\left[\mathrm{W}_{2} \mathrm{Cp}_{2}\left\{\mu-\mathrm{OCH}_{2}(p\right.\right.$ tol) $\left.\}\left(\mu-\mathrm{PPh}_{2}\right)(\mathrm{NO})_{2}\right]$. Insertion also prevailed in the reactions of $\mathbf{1}$ with $\mathrm{CN}^{t} \mathrm{Bu}$ which, however, involved the competitive formation of new $\mathrm{C}-\mathrm{H}$ or $\mathrm{N}-\mathrm{H}$ bonds, to give a mixture of formimidoyl and aminocarbyne derivatives, $\left[\mathrm{W}_{2} \mathrm{Cp}_{2}\left(\mu-\kappa^{1}: \eta^{2}-\mathrm{HCN} \mathrm{Nu}^{t}\right)(\mu-\right.$ $\left.\left.\mathrm{PPh}_{2}\right)(\mathrm{NO})_{2}\right](\mathrm{W}-\mathrm{W}=3.0177(2) \AA)$ and $\left[\mathrm{W}_{2} \mathrm{Cp}_{2}\left\{\mu-\mathrm{C}\left(\mathrm{NH}^{t} \mathrm{Bu}\right)\right\}\left(\mu-\mathrm{PPh}_{2}\right)(\mathrm{NO})_{2}\right](\mathrm{W}-\mathrm{W}$ $=2.9010(4) \AA)$ respectively, even if the latter was thermodynamically preferred, according to Density Functional Theory calculations. The former represents the first structurally characterized complex displaying a formimidoyl or iminoacyl ligand in the alkenyl-like $\mu-\kappa^{1}: \eta^{2}$ - coordination mode. The reaction of $\mathbf{1}$ with diazomethane proceeded with $\mathrm{N}_{2}$ elimination and $\mathrm{C}-\mathrm{H}$ coupling to yield the agostic methyl-bridged complex $\left[\mathrm{W}_{2} \mathrm{Cp}_{2}\left(\mu-\kappa^{1}: \eta^{2}-\mathrm{CH}_{3}\right)\left(\mu-\mathrm{PPh}_{2}\right)(\mathrm{NO})_{2}\right]$ (calcd. $\mathrm{W}-\mathrm{W}=2.923 \AA$ ), whereas the reaction with $\mathrm{N}_{2} \mathrm{CH}\left(\mathrm{SiMe}_{3}\right)$ proceeded with insertion of the diazoalkane to give the corresponding hydrazonide complex $\left[\mathrm{W}_{2} \mathrm{Cp}_{2}\{\mu\right.$-NH(NCHSiMe 3$\left.\left.)\right\}\left(\mu-\mathrm{PPh}_{2}\right)(\mathrm{NO})_{2}\right]$ $(\mathrm{W}-\mathrm{W}=2.8608(4) \AA)$. The latter was converted under alkaline conditions to the methyldiazenide derivative $\left[\mathrm{W}_{2} \mathrm{Cp}_{2}\{\mu-\mathrm{N}(\mathrm{NMe})\}\left(\mu-\mathrm{PPh}_{2}\right)(\mathrm{NO})_{2}\right](\mathrm{W}-\mathrm{W}=2.8730(2) \AA)$, in a process involving hydrolysis of the $\mathrm{C}-\mathrm{Si}$ bond coupled to a $1,3-\mathrm{H}$ shift from $\mathrm{N}$ to $\mathrm{C}$.
\end{abstract}




\section{Introduction}

Transition-metal nitrosyl complexes constitute a vast family of compounds of interest from many different points of view. ${ }^{1}$ From the most academic side, it must be noted that nitric oxide is an exceptionally versatile molecule being able not only to adopt many different coordination modes, but also to efficiently bind metal atoms both in high and low oxidation states, whereby a large number of coordination and organometallic complexes can be built on, which moreover display a rich stoichiometric and catalytic chemistry. Besides this, nitrosyl complexes are also of interest because nitric oxide has a relevant role in living organisms which depends, inter alia, on its interaction with metal centers, ${ }^{1,2}$ while some nitrosyl complexes can be even designed to release NO in a controlled way within biological media for therapeutic purposes. ${ }^{3}$ Finally, since nitric oxide itself is one of the most important atmospheric pollutants requiring catalytic abatement, ${ }^{1,4,5}$ the study of metal-nitrosyl interactions can lead to the design of more efficient and sustainable catalysts. Most of the research on nitrosyl complexes, however, has been developed so far on mononuclear species, while the chemistry of binuclear complexes remains much less explored, particularly in the case of the very few reported complexes bearing metal-metal multiple bonds, ${ }^{6}$ mainly due to synthetic difficulties or ready degradation to mononuclear species upon reaction with other molecules.

\section{Scheme1}

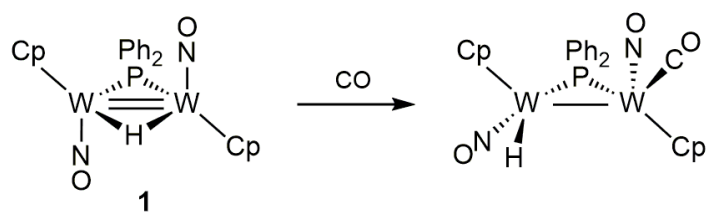

Recently we reported the preparation of the unsaturated nitrosyl hydride $\left[\mathrm{W}_{2} \mathrm{Cp}_{2}(\mu-\right.$ $\left.\mathrm{H})\left(\mu-\mathrm{PPh}_{2}\right)(\mathrm{NO})_{2}\right](\mathbf{1})$, a 32-electron complex stabilized with respect to degradation into mononuclear derivatives by the phosphanyl ligand connecting the tungsten atoms (Scheme 1; $\mathrm{Cp}=\eta^{5}-\mathrm{C}_{5} \mathrm{H}_{5}$ ). ${ }^{6}$ The formal $\mathrm{W}-\mathrm{W}$ double bond proposed for $\mathbf{1}$ on the basis of the $18 \mathrm{e}$ rule $^{7}$ is in agreement with the short intermetallic separation in the molecule (2.7699(7) $\AA$ ), and it can be more precisely described as composed of a bicentric $\mathrm{W}_{2} \sigma$ interaction and a closed tricentric $\mathrm{W}_{2} \mathrm{H}$ interaction, on the basis of Density Functional Theory (DFT) calculations. Besides this, the implied electronic unsaturation of the molecule was proved by the easy addition of a simple ligand as carbon monoxide, to yield the corresponding electron-precise derivative $\left[\mathrm{W}_{2} \mathrm{Cp}_{2}(\mathrm{H})\left(\mu-\mathrm{PPh}_{2}\right)(\mathrm{CO})(\mathrm{NO})_{2}\right]$ (Scheme 1). We should stress that compound 1 is one of the few unsaturated binuclear nitrosyl hydrides reported so far, along with the $\mathrm{W}(\mathrm{III})$ polyhydrides $\left[\mathrm{W}_{2} \mathrm{~L}_{2}(\mu\right.$ $\left.\mathrm{H})_{2} \mathrm{H}_{2}(\mathrm{NO})_{2}\right] \quad\left(\mathrm{L}=\mathrm{Cp}, \mathrm{Cp}^{*}\right), \quad\left[\mathrm{W}_{2} \mathrm{Cp}^{*}{ }_{2}(\mu-\mathrm{H})_{2} \mathrm{H}(\mathrm{R})(\mathrm{NO})_{2}\right], \quad$ and $\left[\mathrm{W}_{2} \mathrm{Cp}^{*}{ }_{2}(\mu-\right.$ 
$\left.\mathrm{H})_{2}(\mathrm{R})\left(\mathrm{R}^{\prime}\right)(\mathrm{NO})_{2}\right]\left(\mathrm{Cp}^{*}=\eta^{5}-\mathrm{C}_{5} \mathrm{Me}_{5}\right){ }^{8}$ Since the chemistry of the latter complexes has not been studied in detail, then it was of interest to explore the chemical behavior of $\mathbf{1}$ in a wide sense. ${ }^{9}$ From an electronic point of view, compound $\mathbf{1}$ can be related to different carbonyl complexes bearing the very reactive 32-electron $\mathrm{M}_{2}(\mu-\mathrm{H})_{2}$ core, such as $\left[\mathrm{Os}_{3}(\mu-\mathrm{H})_{2}(\mathrm{CO})_{10}\right],{ }^{10}\left[\operatorname{Re}_{2}(\mu-\mathrm{H})_{2}(\mathrm{CO})_{8}\right],{ }^{11}$ and $\left[\operatorname{Mn}_{2}(\mu-\mathrm{H})_{2}(\mathrm{CO})_{6}\left(\mu-\mathrm{L}_{2}\right)\right],{ }^{12}$ all of which proved to be very reactive towards a great variety of organic and inorganic molecules under mild conditions. From a structural point of view, however, compound $\mathbf{1}$ is related more closely to the 30-electron carbonyl hydrides $\left[\mathrm{M}_{2} \mathrm{Cp}_{2}(\mu-\mathrm{H})(\mu-\mathrm{PCy})(\mathrm{CO})_{2}\right](\mathrm{M}=$ Mo, W), which also display a wide and remarkable reactivity. ${ }^{13,14}$ In this paper we report our results on the reactions of 1 with several $p$-block element $(\mathrm{E})$ molecules bearing $\mathrm{E}-\mathrm{H}$ bonds, such as $\mathrm{BH}_{3} \cdot \mathrm{THF}, \mathrm{HSnPh}_{3}, \mathrm{HSPh}$ and $(p$-tol $) \mathrm{C}(\mathrm{O}) \mathrm{H}$, so to examine its oxidative addition and dehydrogenation chemistry. We also report our results on reactions with some simple organic molecules bearing $\mathrm{C}-\mathrm{N}$ multiple bonds, such as isocyanides and diazoalkanes, so to examine the insertion chemistry of this hydride complex. Expectedly, compound $\mathbf{1}$ also is reactive toward alkynes, but this chemistry will be reported separately. As it will be shown below, the chemical behavior of $\mathbf{1}$ bears similarities to both the 32- and 30-electron hydride complexes mentioned above, and is characterized by the ready addition of the mentioned molecules under mild conditions, which is invariably followed by additional processes such as $\mathrm{E}-\mathrm{H}$ bond cleavage, dehydrogenation, insertion and denitrogenation.

\section{Results and Discussion}

Reactions of 1 with Molecules Displaying $\mathbf{E}-\mathbf{H}$ bonds ( $\mathrm{E}=\boldsymbol{p}$-block element). Compound 1 reacts readily with excess of the borane adduct $\mathrm{BH}_{3} \cdot \mathrm{THF}$, in toluene solution at room temperature, to give the trihydride complex $\left[\mathrm{W}_{2} \mathrm{Cp}_{2}(\mu-\mathrm{H}) \mathrm{H}_{2}(\mu-\right.$ $\left.\left.\mathrm{PPh}_{2}\right)(\mathrm{NO})_{2}\right](2)$, which is obtained as a 2:1 mixture of two isomers (A and $\mathbf{B}$ ) differing in the position (cis or trans, respectively) of one of the terminal hydride ligands with respect to the $\mathrm{P}$ atom (Scheme 2 and Table 1). The formation of trihydride 2 in this reaction is fully unexpected in view of the known reactivity of hydride-bridged unsaturated complexes. For instance, the dimanganese hydrides $\left[\mathrm{Mn}_{2}(\mu-\mathrm{H})_{2}(\mathrm{CO})_{6}(\mu-\right.$ $\left.\mathrm{L}_{2}\right)$ ] reacted with the same borane adduct to give the corresponding tetrahydroboratebridged derivatives, following from insertion of the $\mathrm{BH}_{3}$ molecule into the $\mathrm{Mn}-\mathrm{H}-\mathrm{Mn}$ bond, ${ }^{12 \mathrm{e}}$ while $\left[\mathrm{Os}_{3}(\mu-\mathrm{H})_{2}(\mathrm{CO})_{10}\right.$ ] reacted with $\mathrm{B}_{2} \mathrm{H}_{6}$ in a complex way to give a cluster bearing a $\mu_{3}$-BCO ligand. ${ }^{15}$ In a formal sense, compound 2 results from hydrogenation (oxidative addition of $\mathrm{H}_{2}$ ) of $\mathbf{1}$, but separated experiments revealed that $\mathbf{1}$ actually failed to react with $\mathrm{H}_{2}$, even under forcing conditions (40 atm, toluene solution, $363 \mathrm{~K}$ ). It must be then concluded that the formation of $\mathbf{2}$ in this reaction follows from a complex sequence of insertion, $\mathrm{B}-\mathrm{H}$ bond cleavage and elimination processes. Unfortunately, no 
intermediate species were detected even when performing this reaction under stoichiometric conditions.

Clean $\mathrm{E}-\mathrm{H}$ bond oxidative addition, however, occurs in the reaction of $\mathbf{1}$ with the organotin hydride $\mathrm{HSnPh}_{3}$, a process also taking place readily at room temperature to give the corresponding dihydride stannyl derivative $\left[\mathrm{W}_{2} \mathrm{Cp}_{2}(\mu-\mathrm{H}) \mathrm{H}(\mu\right.$ $\left.\left.\mathrm{PPh}_{2}\right)(\mathrm{NO})_{2}\left(\mathrm{SnPh}_{3}\right)\right](3)$ in high yield (Scheme 2). Related $\mathrm{Sn}-\mathrm{H}$ bond cleavages were observed in the room temperature reactions of the dimanganese hydrides $\left[\operatorname{Mn}_{2}(\mu\right.$ $\left.\mathrm{H})_{2}(\mathrm{CO})_{6}\left(\mu-\mathrm{L}_{2}\right)\right]$ with $\mathrm{HSnPh}_{3}$ in the presence of $\mathrm{CO},{ }^{12 \mathrm{a}}$ whereas the dimolybdenum hydride $\left[\mathrm{Mo}_{2} \mathrm{Cp}_{2}(\mu-\mathrm{H})\left(\mu-\mathrm{PCy}_{2}\right)(\mathrm{CO})_{2}\right]$ reacted with $\mathrm{HSnPh}_{3}$ with eventual release of hydrogen, thus accomplishing a formal $\mathrm{H} / \mathrm{SnPh}_{3}$ substitution. ${ }^{16}$

Scheme 2. Reactions of 1 with Molecules Having E-H Bonds

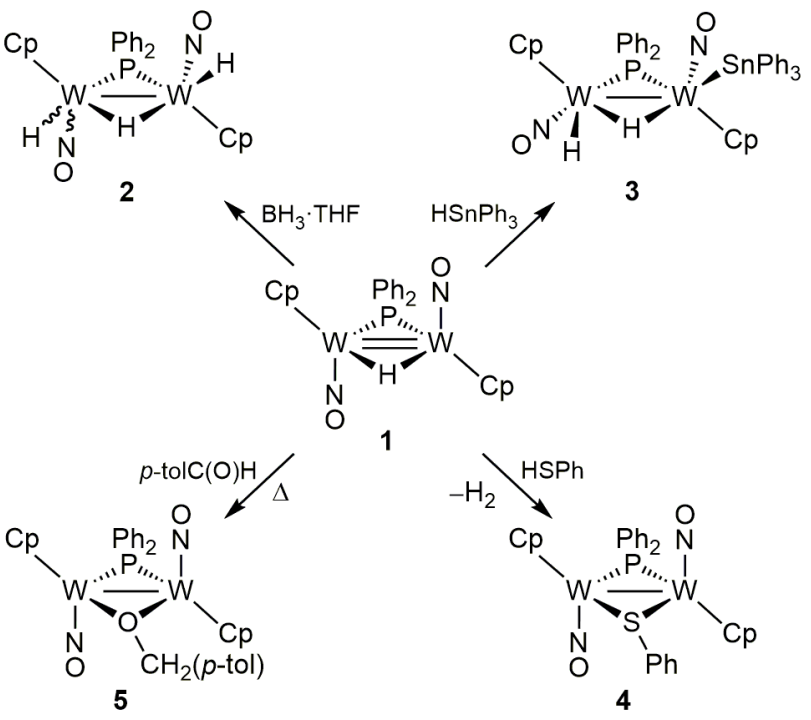

Compound 1 also reacts readily at room temperature with $\mathrm{HSPh}$, now to give selectively the corresponding thiolate-bridged derivative $\left[\mathrm{W}_{2} \mathrm{Cp}_{2}(\mu-\mathrm{SPh})(\mu\right.$ $\left.\left.\mathrm{PPh}_{2}\right)(\mathrm{NO})_{2}\right](4)$, following from a dehydrogenation process accomplishing a net $\mathrm{H} / \mathrm{SPh}$ substitution at the dimetal site (Scheme 2). This behavior is comparable to the one displayed by related unsaturated hydrides, such as $\left[\mathrm{Mn}_{2}(\mu-\mathrm{H})_{2}(\mathrm{CO})_{6}\left(\mu-\mathrm{L}_{2}\right)\right]^{12 \mathrm{c}}$ and $\left[\mathrm{Mo}_{2} \mathrm{Cp}_{2}(\mu-\mathrm{H})(\mu-\mathrm{PCy})(\mathrm{CO})_{2}\right],{ }^{16 a}$ which also yield thiolate derivatives when reacting with thiols.

The formation of compounds $\mathbf{3}$ and $\mathbf{4}$ is likely initiated by coordination of the reagent to the unsaturated ditungsten center, via the $\mathrm{Sn}-\mathrm{H}$ bond or the lone electron pair at sulfur, respectively, to give an electron-precise intermediate D (Scheme 3) similar to the carbonylation derivative of $\mathbf{1}$ depicted in Scheme 1. This intermediate then would evolve via $\mathrm{E}-\mathrm{H}$ bond oxidative addition (OA) to yield $\mathbf{3}$ or, in the thiol reaction, to give a second intermediate $\mathbf{E}$ bearing a terminal thiolate ligand. The latter afterwards would undergo dehydrogenation (note the spatial proximity of the hydride ligands at intermediate $\mathbf{E}$ ) and thiolate rearrangement to the bridging position, thus yielding 4 . A 
question naturally following from this proposal is whether the dihydride $\mathbf{3}$ might be able to undergo dehydrogenation to yield an unsaturated stannyl-bridged derivative. Unfortunately, only a generalized decomposition of the complex was observed when refluxing a toluene solution of $\mathbf{3}$, or when irradiating it with visible-UV light at room temperature.

Scheme 3. Reaction Pathway in the Formation of Compounds 3 and $4^{a}$

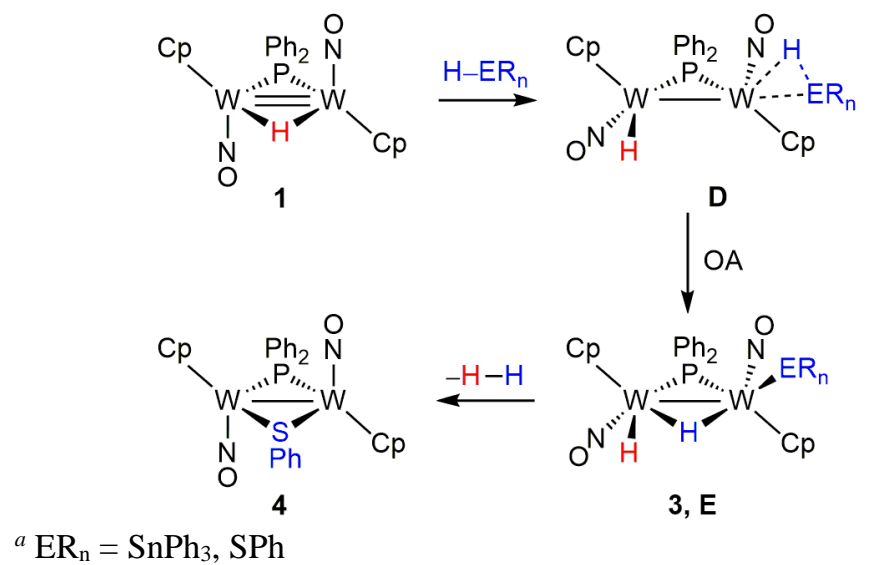

The formation of compounds 3 and $\mathbf{4}$ relies on the cleavage of $\mathrm{H}-\mathrm{Sn}$ and $\mathrm{H}-\mathrm{S}$ bonds, which are bonds of the intermediate strength. Not surprising, reagents bearing the stronger $\mathrm{C}-\mathrm{H}$ bond, such as 1-alkynes and aldehydes, interact with $\mathbf{1}$ in different ways. In the case of the aldehyde $(p$-tol $) \mathrm{C}(\mathrm{O}) \mathrm{H}$, no reaction was observed at room temperature, but refluxing toluene solutions of 1 with a large excess of this reagent led rapidly to the selective formation of the alkoxide derivative $\left[\mathrm{W}_{2} \mathrm{Cp}_{2}\left\{\mu-\mathrm{OCH}_{2}(p\right.\right.$-tol $\left.)\right\}(\mu$ $\left.\left.\mathrm{PPh}_{2}\right)(\mathrm{NO})_{2}\right](5$, Scheme 2). This product follows from insertion of the reagent into the $\mathrm{W}-\mathrm{H}-\mathrm{W}$ bond of the parent substrate, with selective formation of a new and strong $\mathrm{C}-\mathrm{H}$ bond. The likely mechanism of this reaction bears some similarity with the one operating in the reactions of $\mathbf{1}$ with isocyanides, and will be discussed later on. We finally note that the behavior of $\mathbf{1}$ in this reaction is reminiscent of the one displayed by the dimanganese hydrides $\left[\mathrm{Mn}_{2}(\mu-\mathrm{H})_{2}(\mathrm{CO})_{6}\left(\mu-\mathrm{L}_{2}\right)\right]{ }^{12 \mathrm{c}}$ and also by the 30-electron complex $\left[\mathrm{W}_{2} \mathrm{Cp}_{2}(\mathrm{H})(\mu-\mathrm{PCy})(\mathrm{CO})_{2}\right]$. In the latter case, however, the corresponding alkoxide complex was only an intermediate species, which eventually evolved via an unusual $\mathrm{C}-\mathrm{O}$ bond cleavage process at the alkoxide ligand, to yield an oxo alkyl derivative. $^{17}$

Structural Characterization of Polyhydride Derivatives 2 and 3. As noticed above, compound 2 was obtained as a mixture of two isomers. The ${ }^{1} \mathrm{H}$ NMR spectrum of the major isomer $\mathbf{2 A}$ (see the Experimental Section) indicates the presence in the molecule of two inequivalent terminal hydrides $\left(\delta-1.09 \mathrm{ppm}, J_{\mathrm{HP}}=13, J_{\mathrm{HW}}=77 \mathrm{~Hz}\right.$, and $\left.\delta-1.70, J_{\mathrm{HP}}=40, J_{\mathrm{HW}}=98\right)$, and a third hydride ligand bridging the tungsten atoms $\left(\delta-7.67, J_{\mathrm{HP}}=20, J_{\mathrm{HW}}=53\right)$, as revealed by the chemical shifts and relative intensities 
of the ${ }^{183} \mathrm{~W}$ satellite lines in the respective resonances. In contrast, the minor isomer $\mathbf{2 B}$ bears equivalent terminal hydrides $\left(\delta-0.29, J_{\mathrm{HP}}=12, J_{\mathrm{HW}}=73\right)$ and a bridging hydride ligand $\left(\delta-4.50, J_{\mathrm{HP}}=26, J_{\mathrm{HW}}=51\right)$. We note that the $\mathrm{H}-\mathrm{W}$ coupling of ca. $50 \mathrm{~Hz}$ for the bridging hydride in these isomers is dramatically lower than the corresponding coupling in the parent compound $1(145 \mathrm{~Hz})$, an effect consistent with the increased coordination number (and oxidation state) of the $\mathrm{W}$ atoms in $2 .{ }^{18}$ A similar effect can be appreciated for the $\mathrm{P}-\mathrm{W}$ couplings of the phosphanyl ligand, which fall from $275 \mathrm{~Hz}$ (in 1) to ca. $200 \mathrm{~Hz}$ (Table 1). Moreover, we note that the $\mathrm{H}-\mathrm{W}$ couplings of the bridging hydrides also are significantly lower than those of the terminal hydrides $(73-98 \mathrm{~Hz})$, in agreement with the higher coordination number of bridging hydrides. In contrast, we should recall that in the structurally (but not electronically) related tetrahydride complex $\left[\mathrm{W}_{2} \mathrm{Cp}_{2}(\mu-\mathrm{H})_{2} \mathrm{H}_{2}(\mathrm{NO})_{2}\right]$, the $\mathrm{H}-\mathrm{W}$ couplings of terminal and bridging hydrides were of comparable magnitude $(90-100 \mathrm{~Hz}){ }^{8 \mathrm{a}, \mathrm{b}}$ On the other side, we note that the $\mathrm{H}-\mathrm{W}$ coupling for the hydride-bridged isomer of the 30-electron complex $\left[\mathrm{W}_{2} \mathrm{Cp}_{2} \mathrm{H}(\mu\right.$ $\left.\left.\mathrm{PCy}_{2}\right)(\mathrm{CO})_{2}\right]$ was clearly higher than the coupling for the isomer bearing a terminal hydride (121 vs. $99 \mathrm{~Hz}$ ). ${ }^{14 \mathrm{c}}$ Thus, it seems that the presence of $\mathrm{W}-\mathrm{W}$ multiple bonding can be associated with an increased $\mathrm{H}-\mathrm{W}$ coupling for any hydride ligand bridging these unsaturated dimetal centers, an observation itself consistent with the trends observed previously for different complexes having unsaturated $\mathrm{W}(\mu \text {-H })_{2} \mathrm{M}$ cores. ${ }^{8 \mathrm{~b}}$ Of course such an effect would be absent in the case of the electron-precise complex 2 , thus explaining the low $\mathrm{H}-\mathrm{W}$ couplings of the bridging hydride ligands in this case.

Table 1. Selected IR, ${ }^{a}$ and ${ }^{31} \mathrm{P}\left\{{ }^{1} \mathrm{H}\right\}$ Data ${ }^{b}$ for New Compounds.

\begin{tabular}{|c|c|c|}
\hline Compound & $v(\mathrm{NO})$ & $\delta(\mathrm{P})\left[J_{\mathrm{PW}}\right]$ \\
\hline$\left[\mathrm{W}_{2} \mathrm{Cp}_{2}(\mu-\mathrm{H})\left(\mu-\mathrm{PPh}_{2}\right)(\mathrm{NO})_{2}\right](\mathbf{1})^{c}$ & $1580(\mathrm{w}, \mathrm{sh}), 1552$ (vs) & $212.8[375]$ \\
\hline cis,trans $-\left[\mathrm{W}_{2} \mathrm{Cp}_{2}(\mu-\mathrm{H}) \mathrm{H}_{2}\left(\mu-\mathrm{PPh}_{2}\right)(\mathrm{NO})_{2}\right](\mathbf{2} \mathbf{A})$ & $1593(\mathrm{vs})$ & $76.4[232,177]$ \\
\hline trans,trans- $\left[\mathrm{W}_{2} \mathrm{Cp}_{2}(\mu-\mathrm{H}) \mathrm{H}_{2}\left(\mu-\mathrm{PPh}_{2}\right)(\mathrm{NO})_{2}\right](\mathbf{2 B})$ & $1593(\mathrm{vs})^{d}$ & $50.5[231]$ \\
\hline$\left[\mathrm{W}_{2} \mathrm{Cp}_{2}(\mu-\mathrm{H}) \mathrm{H}\left(\mu-\mathrm{PPh}_{2}\right)(\mathrm{NO})_{2}\left(\mathrm{SnPh}_{3}\right)\right](3)$ & 1597 (vs) & $57.2[233,233]^{e}$ \\
\hline$\left[\mathrm{W}_{2} \mathrm{Cp}_{2}(\mu-\mathrm{SPh})\left(\mu-\mathrm{PPh}_{2}\right)(\mathrm{NO})_{2}\right](\mathbf{4})$ & $1583(w, s h), 1557$ (vs) & $131.0[363,363]$ \\
\hline$\left[\mathrm{W}_{2} \mathrm{Cp}_{2}\left\{\mu-\mathrm{OCH}_{2}(p\right.\right.$-tol $\left.\left.)\right\}\left(\mu-\mathrm{PPh}_{2}\right)(\mathrm{NO})_{2}\right](\mathbf{5})$ & 1557 (w, sh), 1532 (vs) & $135.9[399,399]$ \\
\hline$\left[\mathrm{W}_{2} \mathrm{Cp}_{2}\left(\mu-\kappa^{1}: \eta^{2}-\mathrm{HCN} \mathrm{N}^{t} \mathrm{Bu}\right)\left(\mu-\mathrm{PPh}_{2}\right)(\mathrm{NO})_{2}\right](\mathbf{6})$ & $1572(\mathrm{w}, \mathrm{sh}), 1550(\mathrm{vs})$ & $127.8[350,272]$ \\
\hline$\left[\mathrm{W}_{2} \mathrm{Cp}_{2}\left\{\mu-\mathrm{C}\left(\mathrm{NH}^{t} \mathrm{Bu}\right)\right\}\left(\mu-\mathrm{PPh}_{2}\right)(\mathrm{NO})_{2}\right](7)$ & $1558(\mathrm{w}, \mathrm{sh}), 1541(\mathrm{vs})^{f}$ & $113.6[362,362]$ \\
\hline$\left[\mathrm{W}_{2} \mathrm{Cp}_{2}\left(\mu-\kappa^{1}: \eta^{2}-\mathrm{CH}_{3}\right)\left(\mu-\mathrm{PPh}_{2}\right)(\mathrm{NO})_{2}\right](\mathbf{8})$ & 1571 (w, sh), 1546 (vs) & $130.7[364]$ \\
\hline$\left[\mathrm{W}_{2} \mathrm{Cp}_{2}\left\{\mu-\mathrm{NH}\left(\mathrm{NCHSiMe}_{3}\right)\right\}\left(\mu-\mathrm{PPh}_{2}\right)(\mathrm{NO})_{2}\right](\mathbf{9})$ & $1574(\mathrm{~m}, \mathrm{sh}), 1543(\mathrm{vs})$ & $125.6[387,387]$ \\
\hline$\left[\mathrm{W}_{2} \mathrm{Cp}_{2}\{\mu-\mathrm{N}(\mathrm{NMe})\}\left(\mu-\mathrm{PPh}_{2}\right)(\mathrm{NO})_{2}\right](\mathbf{1 0})$ & $1582(\mathrm{w}, \mathrm{sh}), 1554$ (vs) & $126.7[381,381]$ \\
\hline
\end{tabular}

${ }^{a}$ Recorded in dichloromethane solution, with $\mathrm{N}-\mathrm{O}$ stretching bands $[v(\mathrm{NO})]$ in $\mathrm{cm}^{-1} .{ }^{b}$ Recorded in $\mathrm{CD}_{2} \mathrm{Cl}_{2}$ solution at $121.49 \mathrm{MHz}$ and $293 \mathrm{~K}$, with chemical shifts $(\delta)$ in ppm and ${ }^{31} \mathrm{P}_{-}{ }^{183} \mathrm{~W}$ couplings $\left(J_{\mathrm{PW}}\right)$ in Hz. ${ }^{c}$ Data taken from ref. $6 .{ }^{d}$ Estimated from the spectrum of the mixture of isomers (see text). ${ }^{e} J_{\mathrm{P} 119 \mathrm{Sn}}$ $\approx J_{\mathrm{P} 117 \mathrm{Sn}}=68 \mathrm{~Hz} .{ }^{f} v(\mathrm{NH})=3210(\mathrm{w})$ in Nujol mull. 
The observed isomers of compound 2 mainly differ in the two-bond $\mathrm{H}-\mathrm{P}$ coupling displayed by their terminal hydrides, which are low for the equivalent hydrides in the minor isomer $\mathbf{B}(12 \mathrm{~Hz})$, whereas the inequivalent hydrides of the major isomer $\mathbf{A}$ display $\mathrm{H}-\mathrm{P}$ couplings of 13 and $40 \mathrm{~Hz}$, respectively. This indicates that the terminal hydrides in isomer $\mathbf{B}$ are positioned trans to the $\mathrm{P}$ atoms (Chart 1), while in the major isomer $\mathbf{A}$ one of them is positioned trans and the other one $c$ is to the $\mathrm{P}$ atom. ${ }^{19}$

\section{Chart 1}

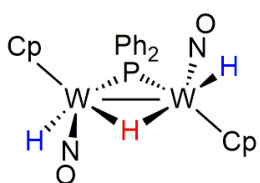

$2 A$

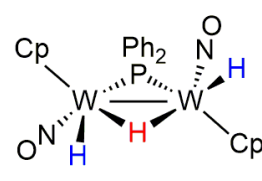

2B

Spectroscopic data for the stannyl compound $\mathbf{3}$ are comparable to those of isomer $\mathbf{B}$ of the trihydride 2 , notably those concerning the chemical shifts and couplings of the $\mathrm{P}$ and hydride atoms, which now also display couplings to the Sn atom, as expected. In particular, its ${ }^{1} \mathrm{H}$ NMR spectrum denotes the presence of a terminal hydride trans to the $\mathrm{P}$ atom $\left(\delta-0.52, J_{\mathrm{HP}}=13, J_{\mathrm{HW}}=68\right)$ and a hydride ligand bridging inequivalent $\mathrm{W}$ atoms $\left(\delta-5.23, J_{\mathrm{HP}}=26, J_{\mathrm{HW}}=55,50\right)$. The positioning of the $\mathrm{SnPh}_{3}$ group trans to the $\mathrm{PCy}_{2}$ ligand, which can be induced from the similitude of the ${ }^{31} \mathrm{P}$ chemical shifts and $\mathrm{P}-\mathrm{W}$ couplings for $\mathbf{3}$ and $\mathbf{2 B}$ (Table 1), is also the one that expectedly would minimize the steric repulsions between the bulky $\mathrm{PCy}_{2}$ and $\mathrm{SnPh}_{3}$ groups surrounding the dimetal centre in compound $\mathbf{3}$.

Structural Characterization of Complexes 4 and 5. Spectroscopic data in solution for compounds 4 and 5 (Table 1 and Experimental Section) are comparable to each other and to those of related complexes of type trans-[M $\left[\mathrm{M}_{2} \mathrm{Cp}_{2}\left(\mu-\mathrm{PR}_{2}\right)(\mu-\mathrm{X})(\mathrm{NO})_{2}\right](\mathrm{M}=$ Mo, $\mathrm{W} ; \mathrm{X}=3$-electron donor) previously prepared by us, then requiring only a few comments. The trans arrangement of the $\mathrm{M}_{2}(\mathrm{NO})_{2}$ core is indicated by the presence of two $\mathrm{N}-\mathrm{O}$ stretches with weak and strong intensity, in order of decreasing frequency, as found for related $\mathrm{M}_{2}(\mathrm{CO})_{2}$ oscillators, ${ }^{1 \mathrm{a}, 20,21}$ and the chemical shift of ca. $135 \mathrm{ppm}$ for the $\mathrm{PPh}_{2}$ ligand in these compounds is comparable to those measured for related complexes of type trans- $\left[\mathrm{W}_{2} \mathrm{Cp}_{2}\left(\mu-\mathrm{PPh}_{2}\right)(\mu-\mathrm{X})(\mathrm{NO})_{2}\right]\left(\mathrm{X}=\mathrm{I}, \mathrm{SMe}\right.$ or $\left.\mathrm{PPh}_{2}\right){ }^{6,22}$ There are, however, significant differences in the one-bond $\mathrm{P}-\mathrm{W}$ couplings when changing $\mathrm{X}$ in this family of compounds, a matter to be discussed later on. We also note that the pyramidal environment around the $\mathrm{S}$ and $\mathrm{O}$ atoms of the bridging ligands in $\mathbf{4}$ and $\mathbf{5}$ renders inequivalent $\mathrm{W}$ centers, which is reflected in the observation of two distinct NMR resonances for the cyclopentadienyl ligands in each case. However, the couplings of the $\mathrm{P}$ nucleus to the inequivalent $\mathrm{W}$ nuclei are identical to each other in both compounds, which we consider as accidental. 
Reactions of 1 with $\mathbf{C N}^{t} \mathrm{Bu}$ : $\mathbf{C}-\mathbf{H}$ and $\mathbf{N}-\mathbf{H}$ Bond Formation. Compound 1 reacts readily at room temperature with the isocyanide $\mathrm{CN}^{t} \mathrm{Bu}$ to give a mixture of two isomers, identified as the formimidoyl complex $\left[\mathrm{W}_{2} \mathrm{Cp}_{2}\left(\mu-\kappa^{1}: \eta^{2}-\mathrm{HCN}{ }^{t} \mathrm{Bu}\right)(\mu-\right.$ $\left.\left.\mathrm{PPh}_{2}\right)(\mathrm{NO})_{2}\right](6)$, and the aminocarbyne complex $\left[\mathrm{W}_{2} \mathrm{Cp}_{2}\left\{\mu-\mathrm{C}\left(\mathrm{NH}^{t} \mathrm{Bu}\right)\right\}\left(\mu-\mathrm{PPh}_{2}\right)(\mathrm{NO})_{2}\right]$ (7) respectively (Scheme 4). These products follow from insertion of the isocyanide into the $\mathrm{W}-\mathrm{H}-\mathrm{W}$ bond of the parent substrate, with formation of new $\mathrm{C}-\mathrm{H}$ and $\mathrm{N}-\mathrm{H}$ bonds, respectively. Both processes are well known in the chemistry of complexes displaying unsaturated $\mathrm{M}_{2}(\mu-\mathrm{H})_{\mathrm{x}}$ units, although usually only one of the possible isomers is obtained in each particular reaction. The formation of aminocarbyne complexes in previous reactions seems to be associated with the use of strong donor solvents and might be base-catalyzed. ${ }^{23}$ However, we note that the 32-electron ditungsten hydride $\left[\mathrm{W}_{2} \mathrm{Cp}_{2}(\mu-\mathrm{H})_{2}(\mathrm{CO})_{4}\right]$ reacted with $\mathrm{CNMe}$ in toluene solution at room temperature to selectively yield the corresponding aminocarbyne derivative, ${ }^{24}$ this suggesting that intramolecular pathways might also lead to the eventual formation of $\mathrm{N}-\mathrm{H}$ bonds. Unfortunately, we have not been able to find experimental conditions to fully drive the above reactions of $\mathbf{1}$ toward one or another product, although separated experiments indicated that formation of the formimidoyl derivative $\mathbf{6}$ was prevalent when carrying out the reaction at room temperature, whereas the aminocarbyne complex 7 was preferentially formed when performing the reaction at $273 \mathrm{~K}$, while keeping a low isocyanide concentration during the process (see the Experimental Section). Fortunately, we could obtain pure samples of each of these products through crystallization, this allowing for their full structural characterization (see below).

Scheme 4. Reaction of 1 with $\mathrm{CN}^{t} \mathrm{Bu}$

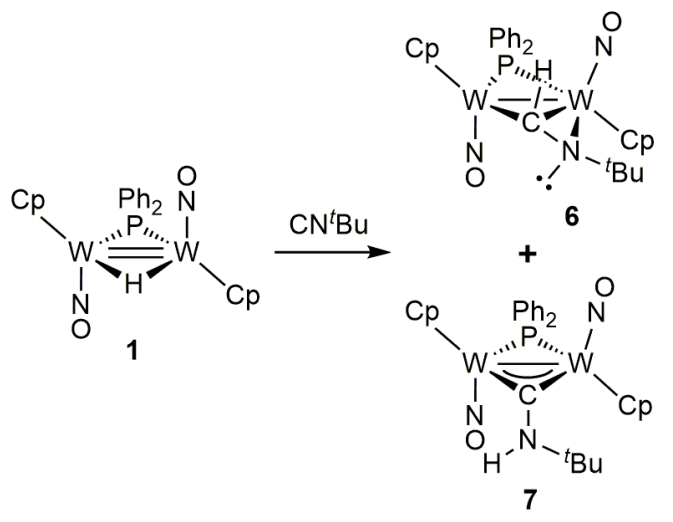

In a previous study on the reactions of several isocyanides with the 30-electron hydride complex $\left[\mathrm{W}_{2} \mathrm{Cp}_{2}(\mathrm{H})\left(\mu-\mathrm{PCy}_{2}\right)(\mathrm{CO})_{2}\right]$ we found that formimidoyl-bridged complexes were formed in all cases, although the corresponding aminocarbyne isomers were computed to be thermodynamically much more stable. ${ }^{14 \mathrm{~b}}$ Interestingly, we observed one example of formimidoyl/aminocarbyne isomerization in the case of the CNXyl derivative, which displayed a 3 -electron donor $\mu-\kappa^{1}: \kappa^{1}$-formimidoyl ligand and 
rearranged slowly at room temperature. This rare isomerization could not be accomplished in the case of our nitrosyl complexes. In fact, refluxing toluene solutions of mixtures of compounds $\mathbf{6}$ and $\mathbf{7}$ operated no significant change in the mixture, while exposing these solutions to the visible-UV light just caused a generalized decomposition of both products.

The failure of $\mathbf{6}$ and $\mathbf{7}$ to interconvert upon thermal activation indicates that these isomers must be formed through different mechanisms, which however might have some common points to the one operating in the formation of the aldehyde derivative 5 (Scheme 5). The reaction would be initiated in all these cases with the coordination of the organic molecule in a terminal fashion (via $\mathrm{O}$ or $\mathrm{C}$ atoms, respectively) to give an intermediate of type D which now cannot undergo oxidative addition, but can only evolve through insertion. This might be facilitated by a rearrangement of the added molecule into a bridging position (intermediate $\mathbf{F}$ ), which brings it closer to the terminal hydride ligand. The alkoxide and aminocarbyne complexes then would follow from a $\mathrm{H}$-shift to the " $\beta$ " site of the organic molecule ( $\mathrm{H}-\mathrm{X}$ coupling in the Scheme). On the other hand, the migration to the bridgehead atom of the ligand (" $\alpha$ " position, $\mathrm{H}-\mathrm{E}$ coupling in the Scheme), which is an elemental step related to the dehydrogenation step leading to the thiolate complex 4 , only takes place in the $\mathrm{CN}^{t} \mathrm{Bu}$ reaction, and seems to occur at a rate comparable to the one leading to the aminocarbyne complex.

Scheme 5. Reaction Pathways in the Formation of Compounds 5 to $7^{a}$

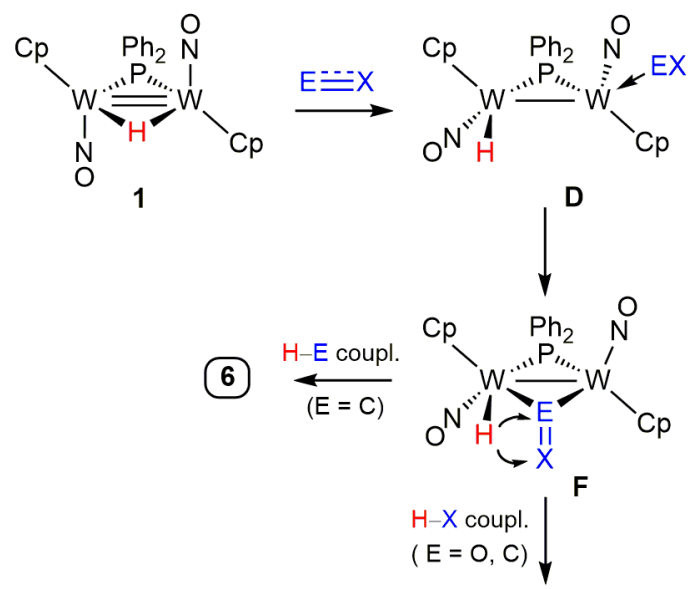

5,7

${ }^{a} \mathrm{EX}=\mathrm{O}=\mathrm{CH}(p-$ tol $), \mathrm{C} \equiv \mathrm{N}^{t} \mathrm{Bu}$

Solid-State Structure of the Formimidoyl Complex 6. The structure of 6 in the crystal (Figure 1 and Table 2) is built up from two $\mathrm{WCp}(\mathrm{NO})$ units in a transoid arrangement and bridged by phosphanyl and formimidoyl ligands. The latter is coordinated in an alkenyl-like fashion, and might be viewed as $\sigma$-bound to one of the tungsten atoms, as indicated by the quite short W2-C1 separation of 2.045(3) $\AA$, and $\pi$ bound to the second metal atom, as indicated by the much longer W1-C1 separation of 
2.353(3) A. This coordination mode still is more closely related to the one found in the isoelectronic acyl complex $\left.\left[\mathrm{Mo}_{2} \mathrm{Cp}_{2}\left\{\mu-\kappa^{1}: \eta^{2}-\mathrm{C}(\mathrm{O}) \mathrm{Me}\right\}(\mu-\mathrm{PCy})_{2}\right)(\mathrm{NO})_{2}\right]$, which displays Mo-C lengths of 2.068(5) and 2.345(5) $\AA^{25}$ The W1-N3 length of 2.142(2) $\AA$ in 6, however, is not particularly enlarged with respect to a conventional single bond (cf. $2.13 \AA$ in the amido-bridged complex $\left.\left[\mathrm{Mo}_{2} \mathrm{Cp}_{2}\left(\mu-\mathrm{NH}_{2}\right)\left(\mu-\mathrm{PCy}_{2}\right)(\mathrm{NO})_{2}\right]\right),{ }^{26}$ but is actually comparable to the lengths of ca. $2.15 \AA$ measured for the same ligand (but $\eta^{2}: \eta^{2}$-bound $)$ in the dicarbonyl complex $\left[\mathrm{W}_{2} \mathrm{Cp}_{2}\left(\mu-\eta^{2}: \eta^{2}-\mathrm{HCN}^{t} \mathrm{Bu}\right)(\mu-\mathrm{PCy})(\mathrm{CO})_{2}\right] .{ }^{14 \mathrm{~b}}$ The strongly asymmetric coordination of the alkenyl ligand in $\mathbf{6}$ is counterbalanced by an unsymmetrical coordination of the phosphanyl ligand, which is positioned some 0.08 $\AA$ closer to the W2 atom. Since the formimidoyl ligand is effectively acting as a 3 electron donor to the dimetal centre, then compound $\mathbf{6}$ can be classified as a 34-electron complex, for which an intermetallic single bond has to be proposed according to the $18 \mathrm{e}$ rule, which is consistent with the W-W separation of 3.0177(2) $\AA$.

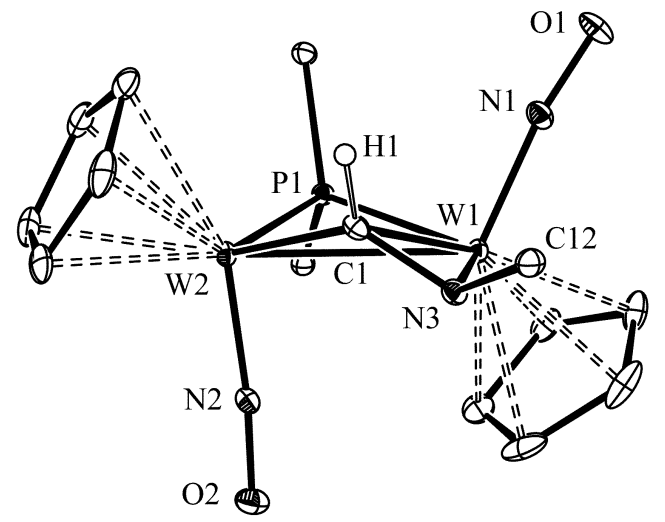

Figure 1. ORTEP diagram (30\% probability) of compound 6, with most $\mathrm{H}$ atoms and ${ }^{t} \mathrm{Bu}$ and $\mathrm{Ph}$ groups (except their $\mathrm{C}^{1}$ atoms) omitted for clarity.

Table 2. Selected Bond Lengths $(\AA)$ and Angles $\left({ }^{\circ}\right)$ for Compound 6

\begin{tabular}{llll}
\hline W1-W2 & $3.0177(2)$ & W1-P1-W2 & $77.05(2)$ \\
W1-P1 & $2.4601(7)$ & W1-C1-W2 & $86.4(1)$ \\
W2-P1 & $2.3840(7)$ & P1-W1-C1 & $88.1(1)$ \\
W1-C1 & $2.353(3)$ & P1-W2-C1 & $98.0(1)$ \\
W2-C1 & $2.045(3)$ & W1-W2-N2 & $81.1(1)$ \\
W1-N1 & $1.772(2)$ & W2-W1-N1 & $113.5(1)$ \\
W1-N3 & $2.142(2)$ & H1-C1-N3 & $117(3)$ \\
W2-N2 & $1.783(2)$ & W2-C1-N3 & $130.0(2)$ \\
C1-N3 & $1.347(4)$ & C1-N3-C12 & $116.8(2)$ \\
N3-C12 & $1.506(4)$ & & \\
\hline
\end{tabular}

We should remark that compound $\mathbf{6}$ is the first structurally characterized example of a molecule bearing a formimidoyl or iminoacyl ligand ( $\mathrm{RCNR}^{\prime}$ ) in the 3-electron donor $\mu-\kappa^{1}: \eta^{2}$ coordination mode ( $\mathbf{B}$ in Chart 2 ). The vast majority of RCNR' complexes structurally characterized to date display these ligands in the 3-electron donor $\mu-\kappa^{1}: \kappa^{1}$ mode (A in Chart 2), with almost planar central $\mathrm{M}_{2} \mathrm{CN}$ cores (about one hundred examples deposited at the Cambridge Crystallographic Database). There are also a few 
examples of complexes with ligands in the 5-electron donor $\mu-\eta^{2}: \eta^{2}$ mode $(\mathbf{C}$ in Chart $2){ }^{14 \mathrm{~b}}$ with tetrahedral $\mathrm{M}_{2} \mathrm{CN}$ cores, and of the planar $\mu-\kappa^{1}: \eta^{2}$ coordination mode (D in Chart 2, specifically formimidoyl complexes). ${ }^{27} \mathrm{We}$ note that the latter mode implies a contribution to the dimetal site between 3 and 5 electrons, depending on the degree of $\pi$ bonding interaction ( $\mathrm{N}$ to $\mathrm{M}$ ). In mode $\mathbf{A}$, the $\mathrm{C}-\mathrm{N}$ bond of the ligand is close to a double bond, and the experimental lengths determined for these complexes accordingly fall typically in the range 1.25-1.34 $\AA$, not far from the reference $\mathrm{C}=\mathrm{N}$ bond length of ca. $1.27 \AA .{ }^{28}$ In contrast, in mode $\mathbf{C}$ the $\mathrm{C}-\mathrm{N}$ bond is close to a single bond, and the corresponding distance accordingly approaches the reference single-bond length of 1.40 $\AA$ for a N-C(sp) bond, ${ }^{29}$ as found in $\left[\mathrm{W}_{2} \mathrm{Cp}_{2}\left(\mu-\eta^{2}: \eta^{2}-\mathrm{HCN}^{t} \mathrm{Bu}\right)(\mu-\mathrm{PCy})(\mathrm{CO})_{2}\right](1.39(1)$ $\AA) .{ }^{14 \mathrm{~b}}$ The coordination mode $\mathbf{B}$ might be viewed as intermediate between the extreme modes $\mathbf{A}$ and $\mathbf{C}$, and indeed the experimental C1-N3 length of 1.347(4) $\AA$ in $\mathbf{6}$ falls midway between the distances typically observed for complexes of types $\mathbf{A}$ and $\mathbf{C}$. For comparison, the corresponding $\mathrm{C}-\mathrm{N}$ length of 1.312(7) $\AA$ in the dimolybdenum complex $\left[\mathrm{Mo}_{2} \mathrm{Cp}_{2}\left(\mu-\kappa^{1}: \kappa^{1}-\mathrm{HCNXyl}\right)(\mu-\mathrm{SMe})_{3}\right]$ (incidentally, the unique group 6 complex of type A structurally characterized to date) is significantly shorter, as expected. ${ }^{30}$

\section{Chart 2}

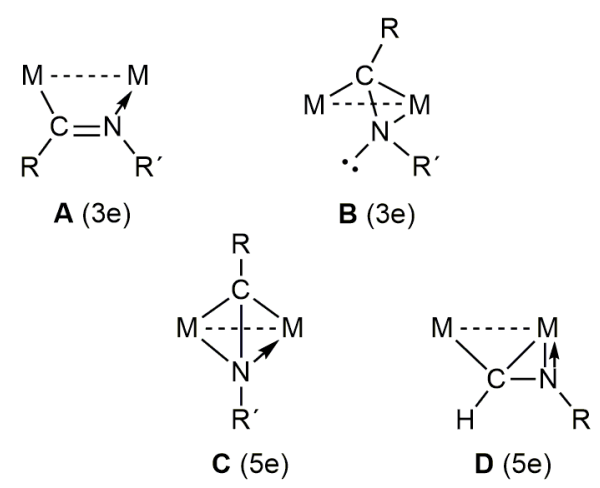

Solid-State Structure of the Aminocarbyne Complex 7. The structure of 7 in the crystal (Figure 2 and Table 3) can be derived from that of $\mathbf{6}$ by replacing the formimidoyl ligand with an equivalent (3-electron donor) aminocarbyne ligand. The latter, however, binds the dimetal centre quite symmetrically, as it does the phosphanyl ligand, and the intermetallic length of 2.9010(4) $\AA$ is ca. $0.12 \AA$ shorter than the corresponding distance in $\mathbf{6}$, an effect likely associated to the reduction in the number of donor atoms at the dimetal site. The central $\mathrm{W}_{2} \mathrm{PC}$ core is slightly puckered (ca. $168^{\circ}$ ), a distortion accompanied by a small deviation of the NO ligands from the antiparallel arrangement found in the parent hydride $1\left(\mathrm{~W}-\mathrm{W}-\mathrm{N}\right.$ ca. $\left.100^{\circ}\right)$, whereby one of the ligands bends away from the dimetal site, and the other one approaches it $(\mathrm{W}-\mathrm{W}-\mathrm{N}$ angles ca. 93 and $107^{\circ}$ in 7). A comparable structural distortion has been found previously in related dicarbonyl complexes of type trans- $\left[\mathrm{M}_{2} \mathrm{Cp}_{2}\left(\mu-\mathrm{PR}_{2}\right)(\mu-\mathrm{X})(\mathrm{CO})_{2}\right]$ 
$(\mathrm{M}=\mathrm{Mo}, \mathrm{W})$ having relatively bulky $\mathrm{R}$ or $\mathrm{X}$ groups, thus pointing to an steric origin of such distortion. ${ }^{31}$ We trust this might also be the case for dinitrosyl $\mathbf{7}$, due to the presence of the bulky ${ }^{\mathrm{t}} \mathrm{Bu}$ group, and for other derivatives of $\mathbf{1}$ to be discussed later on (compounds 9 and 10).

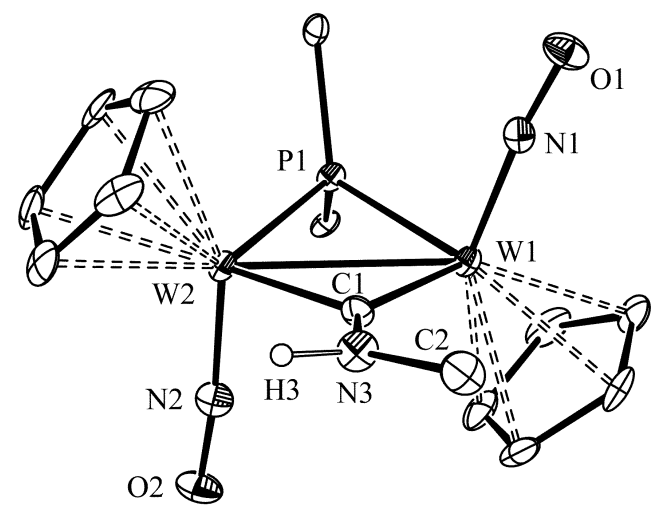

Figure 2. ORTEP diagram (30\% probability) of compound 7, with most $\mathrm{H}$ atoms and ${ }^{t} \mathrm{Bu}$ and $\mathrm{Ph}$ groups (except their $\mathrm{C}^{1}$ atoms) omitted for clarity.

Table 3. Selected Bond Lengths ( $\AA$ ) and Angles $\left({ }^{\circ}\right)$ for Compound 7

\begin{tabular}{llll}
\hline W1-W2 & $2.9010(4)$ & $\mathrm{W} 1-\mathrm{P} 1-\mathrm{W} 2$ & $74.16(4)$ \\
$\mathrm{W} 1-\mathrm{P} 1$ & $2.411(2)$ & $\mathrm{W} 1-\mathrm{C} 1-\mathrm{W} 2$ & $88.1(2)$ \\
$\mathrm{W} 2-\mathrm{P} 1$ & $2.401(1)$ & $\mathrm{P} 1-\mathrm{W} 1-\mathrm{C} 1$ & $97.9(2)$ \\
$\mathrm{W} 1-\mathrm{C} 1$ & $2.086(6)$ & $\mathrm{P} 1-\mathrm{W} 2-\mathrm{C} 1$ & $98.3(2)$ \\
$\mathrm{W} 2-\mathrm{C} 1$ & $2.086(6)$ & $\mathrm{W} 1-\mathrm{W} 2-\mathrm{N} 2$ & $92.7(2)$ \\
$\mathrm{W} 1-\mathrm{N} 1$ & $1.796(5)$ & $\mathrm{W} 2-\mathrm{W} 1-\mathrm{N} 1$ & $106.6(2)$ \\
$\mathrm{W} 2-\mathrm{N} 2$ & $1.788(5)$ & $\mathrm{W} 1-\mathrm{C} 1-\mathrm{N} 3$ & $141.5(4)$ \\
$\mathrm{C} 1-\mathrm{N} 3$ & $1.311(8)$ & $\mathrm{W} 2-\mathrm{C} 1-\mathrm{N} 3$ & $130.3(4)$ \\
$\mathrm{N} 3-\mathrm{C} 2$ & $1.505(9)$ & $\mathrm{C} 1-\mathrm{N} 3-\mathrm{C} 2$ & $131.1(5)$ \\
\hline
\end{tabular}

The aminocarbyne ligand in 7 displays trigonal environments at both the $\mathrm{C} 1$ and N3 atoms, with the tungsten, $\mathrm{C} 1, \mathrm{~N} 3$ and $\mathrm{C} 2$ atoms almost placed in the same plane, a circumstance allowing for optimal $\mathrm{C} 1-\mathrm{N} 3 \pi$ bonding interaction. We recall here that the electronic distribution within coordinated aminocarbyne ligands is usually represented by a combination of aminocarbyne (R1) and iminium (R2) canonical forms, ${ }^{32,33}$ each of them involving different orders for the corresponding $\mathrm{M}-\mathrm{C}$ and $\mathrm{C}-\mathrm{N}$ bonds (Chart 3). Most of the aminocarbyne-bridged complexes structurally characterized to date span relatively short $\mathrm{C}-\mathrm{N}$ lengths, in the range 1.26-1.34 $\AA$, this implying that the iminium contribution is quite significant an all cases. Compound 7 actually displays a short C1-N3 length of $1.311(8) \AA$, close to the $\mathrm{C}=\mathrm{N}$ reference length of $1.27 \AA$, and the $\mathrm{W}-\mathrm{C} 1$ distances $(2.086(6) \AA)$ are comparable to those usually measured for bridging carbonyls, then indicative of single bonds. Therefore, it must be concluded that the iminium form is dominant in the case of complex 7. For comparison, the corresponding $\mathrm{C}-\mathrm{N}$ and $\mathrm{W}-\mathrm{C}$ lengths in the aminocarbyne complex $\left[\mathrm{W}_{2} \mathrm{Cp}_{2}\{\mu-\mathrm{C}(\mathrm{NHXyl})\}(\mu-\right.$ $\left.\left.\mathrm{PC}_{2}\right)(\mu-\mathrm{CO})\right]$ were $1.344(5)$ and ca. $2.02 \AA$ respectively, ${ }^{14 \mathrm{~b}}$ this pointing to a smaller contribution of the iminium form in that case. 


\section{Chart 3}
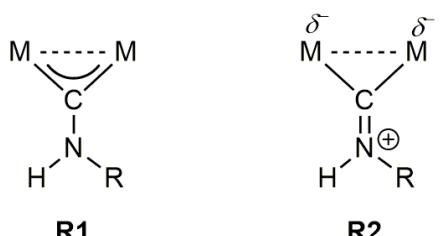

Solution Structure of Complexes 6 and 7. Spectroscopic data in solution for 7 (Table 1 and Experimental section) are consistent with the static structure found in the crystal, and are comparable to those of the thiolate and alkoxide complexes $\mathbf{4}$ and $\mathbf{5}$, or the iodide complex $\left[\mathrm{W}_{2} \mathrm{Cp}_{2}(\mu-\mathrm{I})\left(\mu-\mathrm{PPh}_{2}\right)(\mathrm{NO})_{2}\right],{ }^{6}$ then requiring only a few specific comments concerning the $\mathrm{C}(\mathrm{NHR})$ ligand. The latter gives rise to characteristically deshielded ${ }^{13} \mathrm{C}$ and ${ }^{1} \mathrm{H}$ NMR resonances at 336.0 and 9.99 ppm respectively (cf. 318.8 and $7.22 \mathrm{ppm}$ in $\left.\left[\mathrm{W}_{2} \mathrm{Cp}_{2}\{\mu-\mathrm{C}(\mathrm{NHXyl})\}\left(\mu-\mathrm{PCy}_{2}\right)(\mu-\mathrm{CO})\right]\right)$, and its unsymmetrical nature renders inequivalent metal centers, which is reflected in the appearance of separated cyclopentadienyl resonances. The observation of identical couplings of the $\mathrm{P}$ atom to the metal centers $(365 \mathrm{~Hz})$ then is to be considered as accidental.

As opposed to the above, the strongly unsymmetrical $\mu-\kappa^{1}: \eta^{2}$ coordination of the formimidoyl ligand in $\mathbf{6}$ is denoted by the observation of considerably different couplings of the $\mathrm{P}$ atom to the inequivalent $\mathrm{W}$ atoms (350 and $272 \mathrm{~Hz}$ ), with the lower value being assigned to the coupling with that atom having the higher coordination number (W1 in Figure 1). In contrast, any ditungsten complex displaying formimidoyl or iminoacyl ligands of type A would have similar coordination environments at both metal atoms, and then would be expected to display similar couplings of the $\mathrm{W}$ atoms to any other atom bridging the dimetal center. For instance, the unstable complex $\left[\mathrm{W}_{2} \mathrm{Cp}_{2}\left(\mu-\kappa^{1}: \kappa^{1}-\mathrm{HCNXyl}\right)\left(\mu-\mathrm{PCy}_{2}\right)(\mathrm{CO})_{2}\right]$, a molecule displaying a formimidoyl ligand in the coordination mode $\mathbf{A}$ according to DFT calculations, actually displays identical $\mathrm{P}-\mathrm{W}$ couplings of $207 \mathrm{~Hz}$ to both metal centers. ${ }^{14 \mathrm{~b}}$ The formimidoyl ligand in the latter complex gave rise to quite deshielded ${ }^{13} \mathrm{C}$ and ${ }^{1} \mathrm{H}$ NMR resonances at 215.0 and 12.5 ppm respectively, which is characteristic of formimidoyl complexes in this coordination mode. ${ }^{23 a, 30,34}$ In contrast, formimidoyl complexes of type $\mathbf{C}$ give rise to much more shielded resonances (ca. 45 and $3 \mathrm{ppm}$ respectively for $\left[\mathrm{W}_{2} \mathrm{Cp}_{2}\left(\mu-\eta^{2}: \eta^{2}-\mathrm{HCNR}\right)(\mu-\right.$ $\left.\mathrm{PCy}_{2}\right)(\mathrm{CO})_{2}$ ] complexes). ${ }^{14 \mathrm{~b}}$ Thus, we were surprised to find that the formimidoyl NMR resonances of $\mathbf{6}$ appeared more deshielded than anticipated, at 198.4 and $10.02 \mathrm{ppm}$ respectively, with chemical shifts rather close to the expected values for type $\mathbf{A}$ complexes. This posed some doubts concerning the retention of the $\mu-\kappa^{1}: \eta^{2}$ coordination mode of the formimidoyl ligand in the solutions of $\mathbf{6}$. To throw some additional light on this matter, we carried out DFT calculations on this molecule, and also on the aminocarbyne isomer 7 and an hypothetical isomer $\mathbf{6} \kappa$ having a $C: N$-bridged formimidoyl ligand of type A (Figure 3 and SI). 

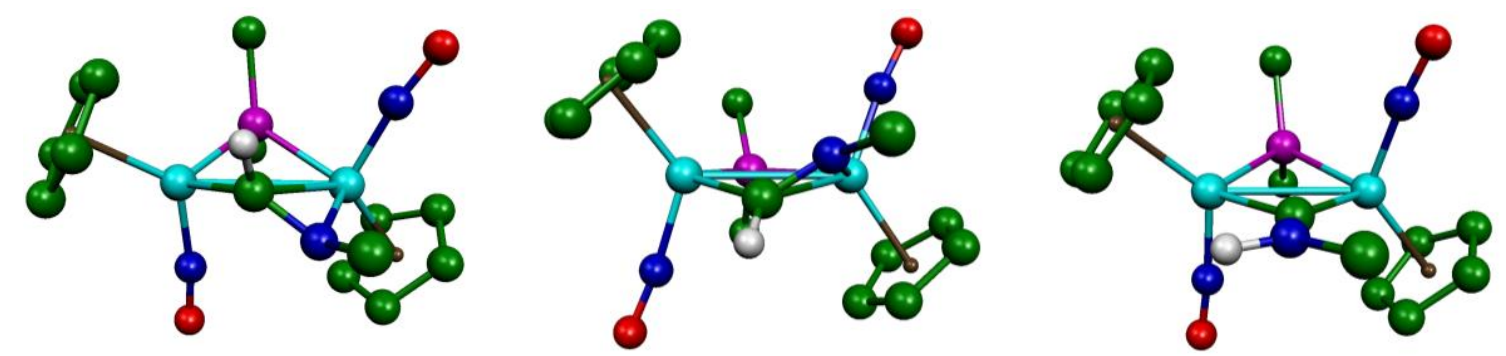

Figure 3. B3LYP-DFT-optimized structures of the formimidoyl complex 6 (left) and the isomers 6' (middle) and 7 (right), with most $\mathrm{H}$ atoms and $\mathrm{Ph}$ and ${ }^{t} \mathrm{Bu}$ groups (except their $\mathrm{C}^{1}$ atoms) omitted, and labeling as in Figures 1 and 2. Relative Gibbs free energies were $+17.5,+34.4$ and $0 \mathrm{~kJ} / \mathrm{mol}$, respectively. Selected bond lengths $(\AA)$ for 6 : W1-W2 $=3.085 ; \mathrm{W} 1-\mathrm{C} 1=2.405 ; \mathrm{W} 2-\mathrm{C} 1=2.055$; W1-N3 = 2.163; $\mathrm{C} 1-\mathrm{N} 3=1.343$. Isomer 6': W1-W2 = 3.093; W1-C1 = 2.641; W2-C1 = 2.085; W1-N3 = 2.131; C1-N3 $=1.321$. Isomer 7: $\mathrm{W} 1-\mathrm{W} 2=2.923 ; \mathrm{W} 1-\mathrm{C} 1=2.078 ; \mathrm{W} 2-\mathrm{C} 1=2.086 ; \mathrm{C} 1-\mathrm{N} 3=1.322$.

First, we note that the DFT-optimized structures for isomers $\mathbf{6}$ and $\mathbf{7}$ are in good agreement with the ones determined in the crystal, although the computed distances involving the metal atoms are somewhat overestimated in general, as commonly found in this type of calculations. ${ }^{35}$ As observed for the dicarbonyl complexes mentioned above, ${ }^{14 \mathrm{~b}}$ we have found that the aminocarbyne complex $\mathbf{7}$ is more stable than any of the formimidoyl isomers, with the $\mu-\kappa^{1}: \eta^{2}$ formimidoyl complex 6 following in Gibbs free energy (18 kJ/mol above 7). We also have found a second $\mu-\kappa^{1}: \eta^{2}$ formimidoyl complex $6^{\prime}$ placed $17 \mathrm{~kJ} / \mathrm{mol}$ above $\mathbf{6}$, with a $\mathrm{W}-\mathrm{C} \pi$ bonding interaction much weaker (W1-C1 ca. $2.64 \AA$; cf. $2.41 \AA$ in 6). Interestingly, a hypothetical isomer with a $\mu-\kappa^{1}: \kappa^{1}$ ligand of type $\mathbf{A}(\mathbf{6} \boldsymbol{\kappa})$ was not a genuine minimum in the potential energy surface of this system. When forced to retain a planar $\mathrm{W}_{2} \mathrm{CN}$ core, the structure of $\mathbf{6} \boldsymbol{\kappa}$ was computed to be $31 \mathrm{~kJ} / \mathrm{mol}$ less stable than $\mathbf{6}$, possibly due to unfavorable steric repulsions between the ${ }^{t} \mathrm{Bu}$ group and a $\mathrm{Cp}$ ligand, which causes a significant weakening of the $\mathrm{W}-\mathrm{N}$ bond (2.21 $\AA$; cf. $2.16 \AA$ in 6). Based on these results, we conclude that compound 6 retains in solution the $\mu-\kappa^{1}: \eta^{2}$ coordination of its formimidoyl ligand, and that the preference of this coordination mode over the more frequent $\mu-\kappa^{1}: \kappa^{1}$ coordination of type $\mathbf{A}$ is steric in origin. On the other hand, we also note that the considerable NMR deshielding of the bridgehead $\mathrm{C}$ atom observed for $\mathbf{6}$, only some $20 \mathrm{ppm}$ below the expected figures for a coordination of type $\mathbf{A}$, is reasonably well reproduced by our calculations [ $\delta_{\mathrm{C}} 213.3$ ppm for $\mathbf{6}$ (exp. 198.4), 240.5 for $\mathbf{6}^{\prime}, 236.9$ for $\mathbf{6} \boldsymbol{\kappa}$ and 354.8 for $\mathbf{7}$ (exp. 336.0)]. This is likely related to the fact that the local environment around this atom in $\mathbf{6}$, excluding the weaker $\pi$ interaction with the second $\mathrm{W}$ atom, remains essentially trigonal, with considerable $\pi(\mathrm{C}-\mathrm{N})$ bonding, thus yielding a shielding not far from those usually found in complexes of type $\mathbf{A}$.

Reactions of 1 with Diazoalkanes. The unsaturated hydride 1 reacts rapidly with diazomethane at room temperature to give selectively the methyl-bridged derivative $\left[\mathrm{W}_{2} \mathrm{Cp}_{2}\left(\mu-\kappa^{1}: \eta^{2}-\mathrm{CH}_{3}\right)\left(\mu-\mathrm{PPh}_{2}\right)(\mathrm{NO})_{2}\right]$ (8) (Scheme 6), a product following from denitrogenation of the diazoalkane and insertion of the resulting methylene group into the $\mathrm{W}-\mathrm{H}-\mathrm{W}$ bond of the parent compound. In contrast, the reaction of $\mathbf{1}$ with 
$\mathrm{N}_{2} \mathrm{CH}\left(\mathrm{SiMe}_{3}\right)$ resulted in no denitrogenation, but in diazoalkane insertion into the $\mathrm{W}-\mathrm{H}-\mathrm{W}$ bond, to give the hydrazonide derivative $\left[\mathrm{W}_{2} \mathrm{Cp}_{2}\left\{\mu-\mathrm{NH}\left(\mathrm{NCHSiMe}_{3}\right)\right\}(\mu\right.$ $\left.\mathrm{PPh}_{2}\right)(\mathrm{NO})_{2}$ ] (9) selectively. Although 9 could by purified through crystallization, this allowing for its full structural characterization, it decomposed completely upon attempted chromatography on alumina, to yield the methyldiazenide complex $\left[\mathrm{W}_{2} \mathrm{Cp}_{2}\{\mu-\mathrm{N}(\mathrm{NMe})\}\left(\mu-\mathrm{PPh}_{2}\right)(\mathrm{NO})_{2}\right](\mathbf{1 0})$ in moderate yield. The transformation of 9 into 10 seems to involve the hydrolysis of the $\mathrm{C}-\mathrm{SiMe}_{3}$ bond (a common process in organic chemistry), and an $1,3-\mathrm{H}$ shift in the resulting $\mu-\mathrm{NHNCH}_{2}$ ligand to render the methyl group eventually present in 10. This transformation could be forced on purpose by stirring a wet dichloromethane solution of $\mathbf{9}$ in the presence of $\mathrm{KOH}$, but water itself did not trigger this reaction.

\section{Scheme 6. Reactions of 1 with Diazoalkanes}

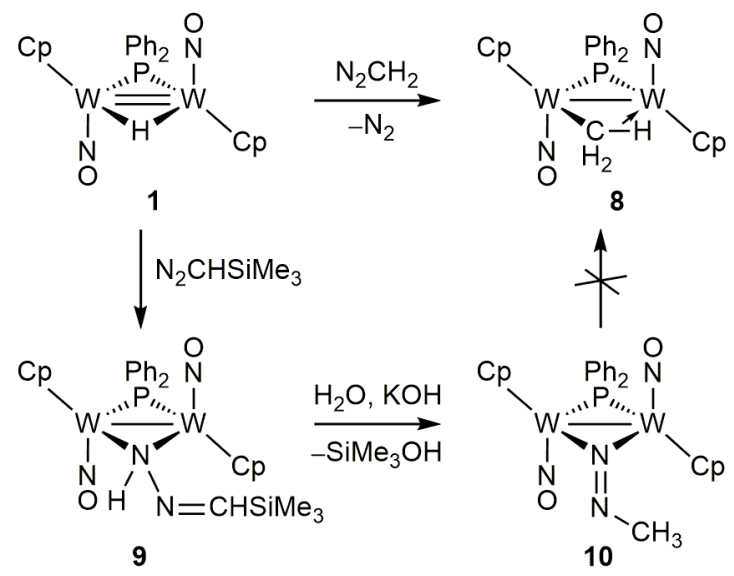

Reactions of diazoalkanes with organometallic complexes having unsaturated $\mathrm{M}_{2}(\mu-$ $\mathrm{H})_{\mathrm{x}}$ cores have been studied in detail only in a limited number of systems, such as the triosmium cluster $\left[\mathrm{Os}_{3}(\mu-\mathrm{H})_{2}(\mathrm{CO})_{10}\right],{ }^{36}$ the 32-electron dirhenium dihydride $\left[\operatorname{Re}_{2}(\mu\right.$ $\left.\mathrm{H})_{2}(\mathrm{CO})_{8}\right],{ }^{37}$ and the 30 -electron ditungsten hydride $\left[\mathrm{W}_{2} \mathrm{Cp}_{2}(\mathrm{H})(\mu-\mathrm{PCy} 2)(\mathrm{CO})_{2}\right],{ }^{14 \mathrm{~d}}$ and the outcome of these reactions usually depends strongly on the particular diazoalkane being used. Diazomethane reacts in all cases with full denitrogenation to yield methyl derivatives, whereas diazoalkane insertion to give hydrazonide derivatives was observed in the reactions of the $\mathrm{Os}_{3}$ and $\mathrm{Re}_{2}$ compounds with other diazoalkanes. ${ }^{36 c, 37 \mathrm{a}}$ The ditungsten hydride was unique in yielding diazoalkane complexes stable with respect to denitrogenation or insertion processes. Thus we conclude that the behavior of $\mathbf{1}$ towards diazoalkanes is closer to the one displayed by the carbonyl complexes bearing 32electron $\mathrm{M}_{2}(\mu-\mathrm{H})_{2}$ centers.

It should be noted that the diazomethane reaction of $\mathbf{1}$ is the unique synthetic route currently available for the methyl complex 8. Attempts to alternatively prepare $\mathbf{8}$ through methylation of the $\mathrm{Na}^{+}$salt of the unsaturated anion $\left[\mathrm{W}_{2} \mathrm{Cp}_{2}\left(\mu-\mathrm{PPh}_{2}\right)(\mathrm{NO})_{2}\right]^{-}$ were unsuccessful. Actually, the reaction of the latter with MeI yielded quantitatively 
the iodide-bridged complex $\left[\mathrm{W}_{2} \mathrm{Cp}_{2}(\mu-\mathrm{I})\left(\mu-\mathrm{PPh}_{2}\right)(\mathrm{NO})_{2}\right]$, whereas the use of halide-free methylation reagents such as $\mathrm{CF}_{3} \mathrm{SO}_{3} \mathrm{Me}$ or $\left[\mathrm{Me}_{3} \mathrm{O}\right] \mathrm{BF}_{4}$ led to mixtures of uncharacterized products, presumably following from oxidation (rather than methylation) of the ditungsten anion.

Structural Characterization of the Agostic Methyl Complex 8. The IR and ${ }^{31} \mathrm{P}$ NMR spectra for $\mathbf{8}$ in solution (Table 1) are comparable to those of complexes $\mathbf{4}$ to $\mathbf{7}$ discussed above, thus indicating the presence of a transoid $\mathrm{W}_{2} \mathrm{Cp}_{2}\left(\mu-\mathrm{PPh}_{2}\right)(\mathrm{NO})_{2}$ fragment further bridged by a 3-electron donor (here, the methyl ligand). The NMR spectra recorded at room temperature expectedly displayed quite shielded resonances for the methyl ligand at $-2.09\left({ }^{1} \mathrm{H}\right)$ and $5.8 \mathrm{ppm}\left({ }^{13} \mathrm{C}\right)$, but also revealed the chemical equivalence of each pair of $\mathrm{Cp}$ and $\mathrm{Ph}$ rings, while no noticeable changes were detected when recording these spectra down to $173 \mathrm{~K}$. All these data would be consistent with either a symmetrical coordination of the methyl ligand $\left(\mu-\kappa^{1}: \kappa^{1}\right)$, or with an $\alpha$-agostic coordination $\left(\mu-\kappa^{1}: \eta^{2}\right)$ coupled to a fast exchange process involving the $\mathrm{H}$ atoms within the methyl group, which also would exchange the metal atom involved in the agostic interaction. Such a fast fluxionality is a common circumstance previously found in different methyl-bridged complexes, such as the dicarbonyl $\left[\mathrm{Mo}_{2} \mathrm{Cp}_{2}\left(\mu-\kappa^{1}: \eta^{2}-\mathrm{CH}_{3}\right)(\mu-\right.$ $\left.\left.\mathrm{PC}_{2}\right)(\mathrm{CO})_{2}\right]$ and related species. ${ }^{38}$ The proposal of an agostic coordination for the methyl ligand in $\mathbf{8}$ is strongly supported by the observation of an averaged $\mathrm{C}-\mathrm{H}$ coupling of just $113 \mathrm{~Hz}$ in this ligand, well below the usual value of $125-130 \mathrm{~Hz}$ expected for conventional $\mathrm{H}-\mathrm{C}\left(s p^{3}\right)$ bonds, and therefore indicative of a quite strong agostic interaction. ${ }^{39}$ Such interaction would actually be much stronger than the one present in the mentioned dicarbonyl complex $\left(J_{\mathrm{CH}}=124 \mathrm{~Hz}\right)$, and comparable to the one present in the highly unsaturated monocarbonyl $\left[\mathrm{Mo}_{2} \mathrm{Cp}_{2}\left(\mu-\kappa^{1}: \eta^{2}-\mathrm{CH}_{3}\right)\left(\mu-\mathrm{P}^{t} \mathrm{Bu}_{2}\right)(\mu-\right.$ $\mathrm{CO})]\left(J_{\mathrm{CH}}=110 \mathrm{~Hz}\right){ }^{31}$ To further support our structural proposal for $\mathbf{8}$ we carried out DFT calculations on both the agostic structure and the non-agostic isomeric form with a $\mu-\kappa^{1}: \kappa^{1}$ ligand, and found that only the agostic structure was a genuine minimum in the potential energy surface of the system (Figure 4). We note that the computed W-W length of $2.923 \AA$ is identical to the one computed for the aminocarbyne complex 7 , thus supporting our view of the agostic methyl ligand in $\mathbf{8}$ as an effective 3 -electron donor to the dimetal center. 


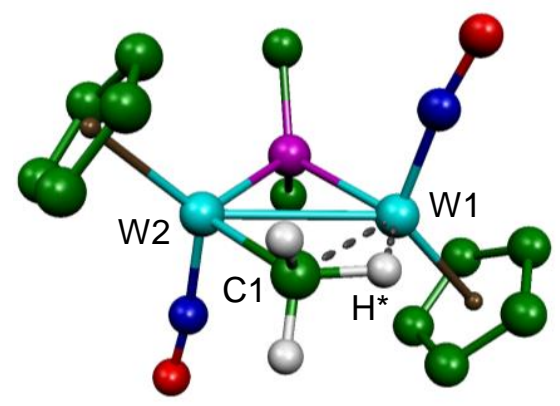

Figure 4. B3LYP-DFT-optimized structure of the agostic methyl complex 8, with most $\mathrm{H}$ atoms and $\mathrm{Ph}$ groups (except their $\mathrm{C}^{1}$ atoms) omitted for clarity. Selected bond lengths $(\AA)$ : $\mathrm{W} 1-\mathrm{W} 2=2.923$; W1-C1 = 2.435; W2-C1 = 2.179; W1-H* = 1.907; C1-H* = 1.180; $\mathrm{C} 1-\mathrm{H}=1.094,1.094$.

Structure of the Hydrazonide Complex 9. The molecule of 9 in the crystal (Figure 5 and Table 4) can be derived from that of the parent compound $\mathbf{1}$ after replacing the hydride ligand with an amide-like bridging hydrazonide ligand, strongly bound to the dimetal centre in a quite symmetrical way $(\mathrm{W}-\mathrm{N} 3=2.097(7)$ and $2.127(6) \AA)$. The structure of 9 is actually very similar to the one recently determined for the amidebridged complex $\left[\mathrm{Mo}_{2} \mathrm{Cp}_{2}\left(\mu-\mathrm{NH}_{2}\right)\left(\mu-\mathrm{PCy}_{2}\right)(\mathrm{NO})_{2}\right]\left(\mathrm{Mo}-\mathrm{N}\right.$ ca. $2.13 \AA$ ) ${ }^{26}$ including the corresponding intermetallic lengths (2.8608(4) $\AA$ in 9 vs. 2.8654(8) $\AA$ in the $\mathrm{Mo}_{2}$ complex), then deserving only a few comments concerning the hydrazonide ligand. The latter expectedly displays a tetrahedral environment around the bridgehead N3 atom, and trigonal environments around the $\mathrm{N} 4$ and $\mathrm{C} 1$ atoms, with the N3-N4 and N4-C1 lengths (1.47(1) and 1.33(1) $\AA$ ) approaching the reference values of 1.42 and $1.27 \AA$ for single and double bonds between the corresponding atoms, respectively. ${ }^{28,29}$ Similar observations have been made on the three other hydrazonide complexes structurally characterized so far, these bearing comparable $\mu-\mathrm{HNNCPh}_{2}$ and $\mu-\mathrm{HNNCPhMe} \mathrm{ligands}$ bridging Os ${ }^{36 c, 40}$ or Re atoms. ${ }^{37 a}$

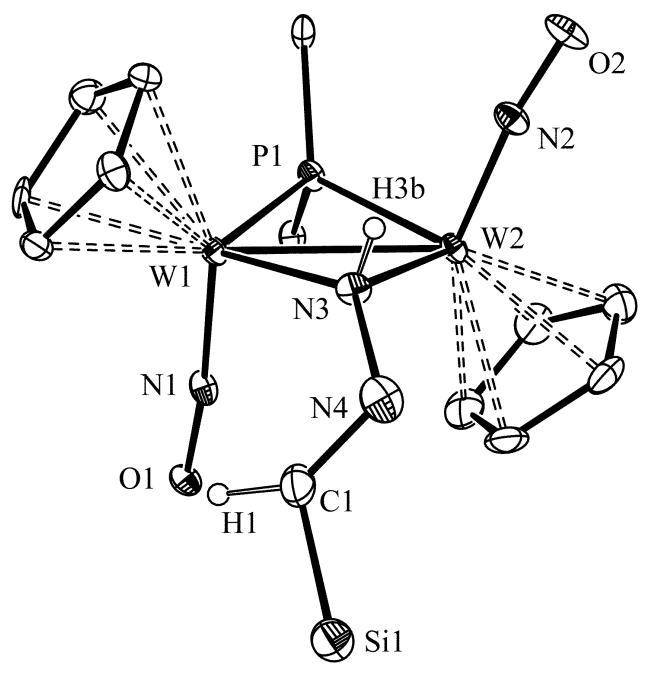

Figure 5. ORTEP diagram (30\% probability) of compound 9, with most $\mathrm{H}$ atoms, Me groups, and $\mathrm{Ph}$ rings (except their $\mathrm{C}^{1}$ atoms) omitted for clarity. 
Table 4. Selected Bond Lengths $(\AA)$ and Angles $\left({ }^{\circ}\right)$ for Compound 9

\begin{tabular}{llll}
\hline W1-W2 & $2.8608(4)$ & W1-P1-W2 & $73.41(6)$ \\
W1-P1 & $2.388(2)$ & W1-N3-W2 & $85.3(2)$ \\
W2-P1 & $2.399(2)$ & P1-W1-N3 & $100.6(2)$ \\
W1-N3 & $2.097(7)$ & P1-W2-N3 & $99.4(2)$ \\
W2-N3 & $2.127(6)$ & W1-W2-N2 & $108.0(2)$ \\
W1-N1 & $1.773(7)$ & W2-W1-N1 & $91.8(2)$ \\
W2-N2 & $1.772(7)$ & W1-N3-N4 & $130.0(5)$ \\
N3-N4 & $1.47(1)$ & W2-N3-N4 & $118.6(5)$ \\
N4-C1 & $1.33(1)$ & N3-N4-C1 & $117.4(8)$ \\
C1-Si1 & $1.84(1)$ & N4-C1-Si1 & $120.0(7)$ \\
\hline
\end{tabular}

Spectroscopic data in solution for 9 (Table 1 and Experimental Section) are comparable to those of the thiolate- and alkoxide complexes $\mathbf{4}$ and $\mathbf{5}$, then deserving no detailed comments. We just note that the inequivalent cyclopentadienyl ligands of the molecule give rise to a single resonance, instead of two, which we consider an accidental coincidence, and that the $\mathrm{NH}$ and olefinic $\mathrm{CH}$ groups of the hydrazonide ligand expectedly give rise to quite deshielded resonances at 8.23 and $8.11 \mathrm{ppm}$, respectively, which were assigned on the basis of their different line widths.

Structure of the Diazenide Complex 10. The molecule of $\mathbf{1 0}$ in the crystal (Figure 6 and Table 5) can be derived from that of the precursor 9 after replacing the hydrazonide group with a $N: N$-bound methyldiazenide ligand, which bridges symmetrically the tungsten atoms even more tightly than before $(\mathrm{W}-\mathrm{N} 3=2.041(3)$ and $2.065(3) \AA)$. The geometrical parameters of the central unit are very similar to those of $\mathbf{9}$, these including the short intermetallic distance $(2.8730(2) \AA)$, the modest puckering of the central $\mathrm{W}_{2} \mathrm{PN}$ core $\left(\mathrm{P}-\mathrm{W}-\mathrm{W}-\mathrm{N}\right.$ angle ca. $\left.168^{\circ}\right)$ and the concomitant departure of the terminal nitrosyls from antiparallel arrangement (W-W-N angles ca. 95 and $\left.104^{\circ}\right)$. The N3 and $\mathrm{N} 4$ atoms of the diazenide ligand display trigonal environments, and the corresponding $\mathrm{N}-\mathrm{N}$ length of 1.246(4) $\AA$ is expectedly very short, actually matching the reference double-bond length of ca. $1.24 \AA^{28}$ Although no comparable methyldiazenide-bridged complexes appear to have been structurally characterized so far, we note that the above $\mathrm{N}-\mathrm{N}$ length is comparable to those previously measured in related aryldiazenidebridged complexes, such as $\left[\mathrm{Mo}_{2} \mathrm{Cp}_{2}(\mu\right.$-NNPh $\left.)(\mu \text {-SMe })_{3}\right](1.255(3) \AA),{ }^{41}$ and $\left[\mathrm{Os}_{3}(\mu\right.$ $\mathrm{H})\{\mu$-NN $(p$-tol $\left.)\}(\mathrm{CO})_{10}\right] \quad(1.233(2) \AA)^{42}$ which, however, were not prepared from diazoalkane reagents. Spectroscopic data in solution for 10 (Table 1 and Experimental Section) are consistent with the asymmetric structure found in the crystal, except for the accidental coincidence of the $\mathrm{P}-\mathrm{W}$ couplings $(381 \mathrm{~Hz})$, but otherwise are comparable to those of $\mathbf{9}$, then deserving no additional comments. 


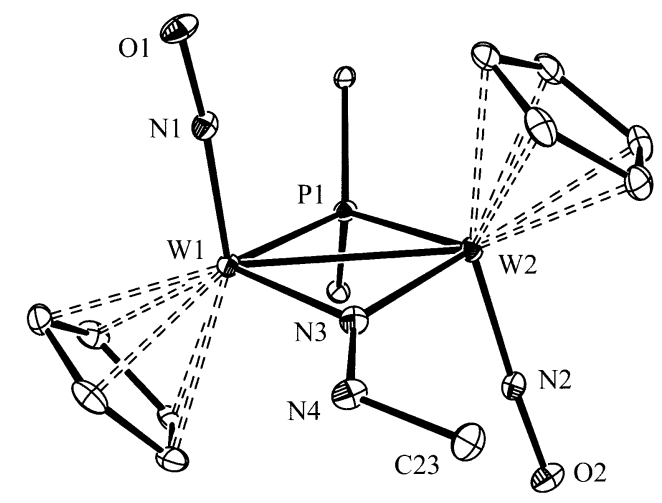

Figure 6. ORTEP diagram (30\% probability) of compound 10, with $\mathrm{H}$ atoms and $\mathrm{Ph}$ rings (except their $\mathrm{C}^{1}$ atoms) omitted for clarity.

Table 5. Selected Bond Lengths $(\AA)$ and Angles $\left({ }^{\circ}\right)$ for Compound 10

\begin{tabular}{llll}
\hline $\mathrm{W} 1-\mathrm{W} 2$ & $2.8730(2)$ & $\mathrm{W} 1-\mathrm{P} 1-\mathrm{W} 2$ & $73.32(2)$ \\
$\mathrm{W} 1-\mathrm{P} 1$ & $2.403(1)$ & $\mathrm{W} 1-\mathrm{N} 3-\mathrm{W} 2$ & $88.8(1)$ \\
$\mathrm{W} 2-\mathrm{P} 1$ & $2.409(1)$ & $\mathrm{P} 1-\mathrm{W} 1-\mathrm{N} 3$ & $98.6(1)$ \\
$\mathrm{W} 1-\mathrm{N} 3$ & $2.041(3)$ & $\mathrm{P} 1-\mathrm{W} 2-\mathrm{N} 3$ & $97.8(1)$ \\
$\mathrm{W} 2-\mathrm{N} 3$ & $2.065(3)$ & $\mathrm{W} 1-\mathrm{W} 2-\mathrm{N} 2$ & $103.5(1)$ \\
$\mathrm{W} 1-\mathrm{N} 1$ & $1.782(3)$ & $\mathrm{W} 2-\mathrm{W} 1-\mathrm{N} 1$ & $94.6(1)$ \\
$\mathrm{W} 2-\mathrm{N} 2$ & $1.788(3)$ & $\mathrm{W} 1-\mathrm{N} 3-\mathrm{N} 4$ & $129.9(2)$ \\
$\mathrm{N} 3-\mathrm{N} 4$ & $1.246(4)$ & $\mathrm{W} 2-\mathrm{N} 3-\mathrm{N} 4$ & $139.5(2)$ \\
$\mathrm{N} 4-\mathrm{C} 23$ & $1.469(4)$ & $\mathrm{N} 3-\mathrm{N} 4-\mathrm{C} 23$ & $116.0(3)$ \\
\hline
\end{tabular}

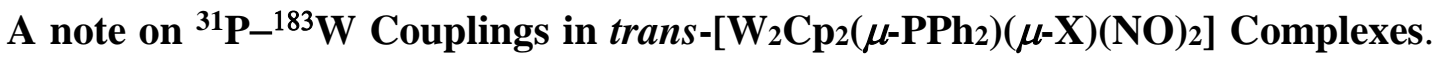
An overall analysis of the ${ }^{31} \mathrm{P}$ NMR parameters of compounds $\mathbf{4 , 5}$, and $\mathbf{7}$ to $\mathbf{1 0}$, as well

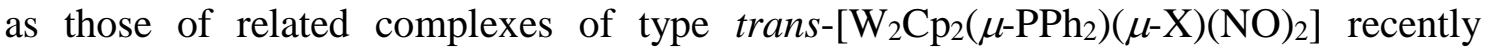
described by us, with ligands $\mathrm{X}=\mathrm{PPh}_{2},{ }^{22} \mathrm{SMe}$ and $\mathrm{I},{ }^{6} \mathrm{Br}$ and $\mathrm{Cl},{ }^{43}$ reveal no clear trends concerning their chemical shifts. In contrast, their one-bond couplings to the tungsten atoms correlate quite well with the Pauling electronegativity $\left(\chi_{P}\right)$ of the bridgehead atom of the ligand $\mathrm{X}$ (Figure 7). This is a general trend for one-bond couplings of any kind, and it is usually explained on the basis that an increase in the electronegativity of a group $\mathrm{X}$ bound to an atom $\mathrm{A}$ (here $\mathrm{W}$ ) leaves electron density with more $s$-character at that atom, thus reinforcing the coupling of atom $A$ to any third atom bound to it (here P) ${ }^{18,44}$ In our context, the interest of this linear correlation for complexes of type trans$\left[\mathrm{W}_{2} \mathrm{Cp}_{2}\left(\mu-\mathrm{PPh}_{2}\right)(\mu-\mathrm{X})(\mathrm{NO})_{2}\right]$ is that, because of its large sensitivity to $\chi_{P}(42 \mathrm{~Hz}$ per unit of electronegativity), the observed $\mathrm{P}-\mathrm{W}$ coupling might reveal the identity of the bridgehead atom in cases where the nature or coordination mode of the bridging ligand $\mathrm{X}$ would be otherwise not obvious. 


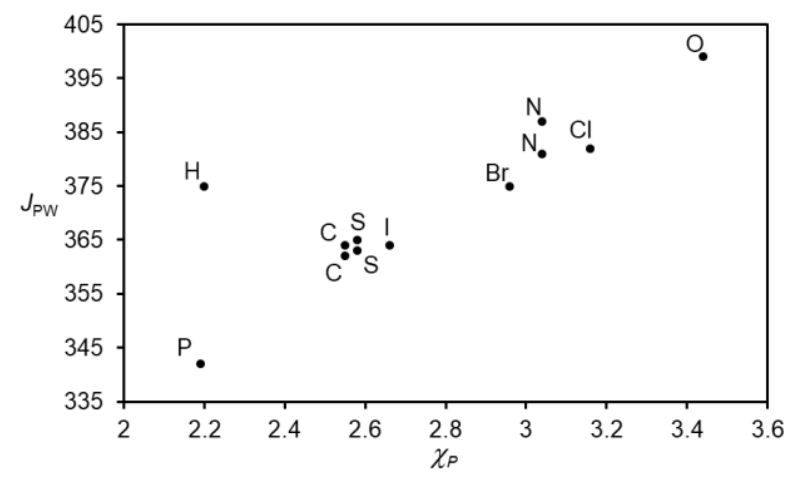

Figure 7. One-bond ${ }^{31} \mathrm{P}-{ }^{183} \mathrm{~W}$ coupling constants $\left(J_{\mathrm{PW}}\right.$, in $\left.\mathrm{Hz}\right)$ for complexes of type trans-[ $\left[\mathrm{W}_{2} \mathrm{Cp}_{2}(\mu-\right.$ $\left.\left.\mathrm{PPh}_{2}\right)(\mu-\mathrm{X})(\mathrm{NO})_{2}\right]$, represented against the Pauling electronegativity $\left(\chi_{P}\right)$ of the bridgehead atom in each $\mathrm{X}$ ligand [X $=\mathrm{H}, \mathrm{PPh}_{2}, \mathrm{CH}_{3}, \mathrm{CNH}^{t} \mathrm{Bu}, \mathrm{SMe}, \mathrm{SPh}, \mathrm{I}, \mathrm{Br}, \mathrm{NHNHSiMe}, \mathrm{NNMe}, \mathrm{Cl}, \mathrm{OCH}_{2}(p$-tol)]. Excluding $\mathrm{H}$, the data fit to the equation $J_{\mathrm{PW}}=253+42 \chi_{P}\left(\right.$ minimum squares, $\left.R^{2}=0.96\right)$.

Finally, we should remark that the parent hydride complex 1 falls apart from the above correlation, since it displays a $\mathrm{P}-\mathrm{W}$ coupling much higher than the one expected on the basis of the hydrogen electronegativity (Figure 7). This can be justified by recalling that complex $\mathbf{1}$ is an unsaturated, 32-electron complex, while all other complexes under consideration are saturated, 34-electron complexes, so the electronic interactions at the bridging region are substantially different from each other. Yet, this provides another example of the higher usefulness of the half-electron convention for interpreting the structural and spectroscopic properties of hydride-bridged organometallic complexes featuring short intermetallic distances. ${ }^{7}$

\section{Concluding Remarks}

As expected for an unsaturated complex, the 32-electron hydride 1 reacts easily under mild conditions with a variety of $p$-block element molecules even if these lack lone electron pairs for initial coordination to the dimetal site $\left(\mathrm{BH}_{3}, \mathrm{HSnPh}_{3}\right)$, but in all cases this event is followed by additional processes. When the added reagent bears a $\mathrm{E}-\mathrm{H}$ bond of medium strength $(\mathrm{E}=\mathrm{B}, \mathrm{Sn}, \mathrm{S})$, then $\mathrm{E}-\mathrm{H}$ bond oxidative addition occurs, which may be followed by dehydrogenation or other processes. Molecules lacking these bonds but displaying $\mathrm{E}-\mathrm{E}^{\prime}$ multiple bonds, such as aldehydes, isocyanides and diazoalkanes, undergo insertion of the added reagent into the $\mathrm{W}-\mathrm{H}-\mathrm{W}$ bond, with formation of new and strong $\mathrm{C}-\mathrm{H}$ and $\mathrm{N}-\mathrm{H}$ bonds. The insertion of $\mathrm{CN}^{t} \mathrm{Bu}$ proceeds through two competitive pathways to give the corresponding aminocarbyne or formimidoyl derivative respectively, the latter displaying an unprecedented $\mu-\kappa^{1}: \eta^{2}$ coordination mode, which is thermodynamically favored over the more usual $\mu-\kappa^{1}: \kappa^{1}$ mode for steric reasons, as suggested by DFT calculations. The reaction with diazomethane proceeds instead with denitrogenation and formal insertion of methylene, to give a product bearing a methyl ligand bridging the metal atoms in an agostic $\mu-\kappa^{1}: \eta^{2}$ coordination mode, according to the available NMR data and DFT calculations. In all, 
the chemical behavior of $\mathbf{1}$ can be related to the reactivity of different carbonyl complexes bearing 32-electron $\mathrm{M}_{2}(\mu-\mathrm{H})_{2}$ cores $(\mathrm{M}=\mathrm{Mn}, \mathrm{Re}, \mathrm{W}, \mathrm{Os})$, but also to the reactivity of the 30-electron hydrides $\left[\mathrm{M}_{2} \mathrm{Cp}_{2}(\mu-\mathrm{H})\left(\mu-\mathrm{PCy}_{2}\right)(\mathrm{CO})_{2}\right](\mathrm{M}=\mathrm{Mo}, \mathrm{W})$, which bear a closer structural relationship with $\mathbf{1}$. A unique property of $\mathbf{1}$ seems to be the ability to yield a stable hydrogenation derivative (the trihydride 2 ), not paralleled by any of the mentioned unsaturated hydrides, which might be related with the presence of two nitrosyl ligands in $\mathbf{1}$, and the proven efficiency of these ligands to stabilize metal complexes both in low and high oxidation states. Most derivatives of $\mathbf{1}$ conform a family of complexes of general formula trans-[ $\left.\mathrm{W}_{2} \mathrm{Cp}_{2}\left(\mu-\mathrm{PPh}_{2}\right)(\mu-\mathrm{X})(\mathrm{NO})_{2}\right]$, where $\mathrm{X}$ typically is a 3-electron donor ligand derived from the added $p$-block element molecule. We have found that the observed $\mathrm{P}-\mathrm{W}$ coupling in these products increases linearly with the Pauling electronegativity of the bridgehead atom of $\mathrm{X}$, a relationship which might be of use for the structural characterization of new complexes in the future.

\section{Experimental Section}

General Procedures and Starting Materials. All manipulations and reactions were carried out under an argon (99.995\%) atmosphere using standard Schlenk techniques. All experiments were carried out using Schlenk tubes equipped with Young's valves. Solvents were purified according to literature procedures and distilled prior to use. ${ }^{45}$ Petroleum ether refers to that fraction distilling in the range 338-343 K. Complex $\left[\mathrm{W}_{2} \mathrm{Cp}_{2}(\mu-\mathrm{H})\left(\mu-\mathrm{PPh}_{2}\right)(\mathrm{NO})_{2}\right](\mathbf{1}),{ }^{6}$ and diethyl ether solutions of diazomethane ${ }^{46}$ were prepared as described previously, while all other reagents were obtained from the usual commercial suppliers and used as received, unless otherwise stated. Chromatographic separations were carried out using jacketed columns cooled by tap water (ca. $288 \mathrm{~K}$ ) or by a closed 2-propanol circuit, kept at the desired temperature with a cryostat. Commercial aluminum oxide (activity I, 70-290 mesh) was degassed under vacuum prior to use. The latter was mixed under argon with the appropriate amount of water to reach activity IV. IR stretching frequencies were generally measured in solution, are referred to as $v$ (solvent), and are given in $\mathrm{cm}^{-1}$. Nuclear magnetic resonance (NMR) spectra were routinely recorded at $293 \mathrm{~K}$ unless otherwise stated. Chemical shifts $(\delta)$ are given in ppm, relative to internal tetramethylsilane $\left({ }^{1} \mathrm{H},{ }^{13} \mathrm{C}\right)$, or external $85 \%$ aqueous $\mathrm{H}_{3} \mathrm{PO}_{4}\left({ }^{31} \mathrm{P}\right)$, and coupling constants $(J)$ are given in $\mathrm{Hz}$.

Preparation of $\left[\mathbf{W}_{2} \mathbf{C p}_{2}\left(\mu-\mathbf{H}_{2} \mathbf{H}_{2}\left(\mu-\mathbf{P P h}_{2}\right)(\mathbf{N O})_{2}\right]\right.$ (2). Excess $\mathrm{BH}_{3} \cdot \mathrm{THF}(250 \mu \mathrm{L}$ of a $1 \mathrm{M}$ solution in THF, $0.25 \mathrm{mmol})$ was added to a toluene solution $(10 \mathrm{~mL})$ of compound $1(0.030 \mathrm{~g}, 0.040 \mathrm{~mol})$, and the mixture was stirred at room temperature for $10 \mathrm{~min}$ to give a yellow solution. Removal of the solvent under vacuum and washing of the residue with petroleum ether $(2 \times 3 \mathrm{~mL})$ gave compound 2 as a yellow solid $(0.024 \mathrm{~g}$, $80 \%$ ). This product was shown (by NMR) to contain a mixture of two isomers ( $2 \mathbf{A}$ and 
2B) in a ratio of ca 2:1 which could not be satisfactorily separated. However, a small amount of the major isomer $\mathbf{2 A}$ could be obtained through fractional crystallization from dichloromethane/petroleum ether mixtures, whereby the spectroscopic data of each of the isomers could be safely assigned. Anal. Calcd for $\mathrm{C}_{22} \mathrm{H}_{23} \mathrm{~N}_{2} \mathrm{O}_{2} \mathrm{PW}_{2}$ : C, 35.42; $\mathrm{H}$, 3.11; N, 3.75. Found: C, 35.05; H, 2.80; N, 3.53. ${ }^{1} \mathrm{H}$ NMR (300.13 MHz, $\mathrm{C}_{6} \mathrm{D}_{6}$, Isomer 2A): $\delta 8.00-6.80(\mathrm{~m}, 10 \mathrm{H}, \mathrm{Ph}), 5.13,4.89(2 \mathrm{~s}, 2 \times 5 \mathrm{H}, \mathrm{Cp}),-0.86\left(\mathrm{~d}, J_{\mathrm{HP}}=13, J_{\mathrm{HW}}=\right.$ $76,1 \mathrm{H}, \mathrm{WH}$ trans $),-1.51\left(\mathrm{dd}, J_{\mathrm{HP}}=40, J_{\mathrm{HH}}=11, J_{\mathrm{HW}}=99,1 \mathrm{H}, \mathrm{WH}\right.$ cis $),-7.48(\mathrm{dd}$, $J_{\mathrm{HP}}=19, J_{\mathrm{HH}}=11, J_{\mathrm{HW}}=53,53,1 \mathrm{H}, \mu$-H). ${ }^{1} \mathrm{H}$ NMR $\left(300.13 \mathrm{MHz}, \mathrm{CD}_{2} \mathrm{Cl}_{2}\right.$, Isomer 2A): $\delta 7.89-7.01(\mathrm{~m}, 10 \mathrm{H}, \mathrm{Ph}), 5.47,5.43(2 \mathrm{~s}, 2$ x $5 \mathrm{H}, \mathrm{Cp}),-1.09\left(\mathrm{~d}, J_{\mathrm{HP}}=13, J_{\mathrm{HW}}=\right.$ $77,1 \mathrm{H}, \mathrm{WH}$ trans $),-1.70\left(\mathrm{dd}, J_{\mathrm{HP}}=40, J_{\mathrm{HH}}=11, J_{\mathrm{HW}}=98,1 \mathrm{H}, \mathrm{WH}\right.$ cis $),-7.67(\mathrm{dd}$, $\left.J_{\mathrm{HP}}=20, J_{\mathrm{HH}}=11, J_{\mathrm{HW}}=53,53,1 \mathrm{H}, \mu-\mathrm{H}\right) .{ }^{1} \mathrm{H} \mathrm{NMR}\left(300.13 \mathrm{MHz}, \mathrm{CD}_{2} \mathrm{Cl}_{2}\right.$, Isomer 2B): $\delta 7.95-7.00(\mathrm{~m}, 10 \mathrm{H}, \mathrm{Ph}), 5.56(\mathrm{~s}, 10 \mathrm{H}, \mathrm{Cp}),-0.29\left(\mathrm{dd}, J_{\mathrm{HP}}=12, J_{\mathrm{HH}}=2, J_{\mathrm{HW}}=\right.$ $73,2 \mathrm{H}, \mathrm{WH}$ trans $),-4.50\left(\mathrm{dt}, J_{\mathrm{HP}}=26, J_{\mathrm{HH}}=2, J_{\mathrm{HW}}=51,1 \mathrm{H}, \mu-\mathrm{H}\right)$.

Preparation of $\left[\mathbf{W}_{2} \mathbf{C p}_{2}(\mu-\mathbf{H}) \mathbf{H}\left(\mu-\mathbf{P P h}_{2}\right)(\mathbf{N O})_{2}\left(\mathbf{S n P h}_{3}\right)\right]$ (3). Solid $\mathrm{HSnPh}_{3}(0.025 \mathrm{~g}$, $0.071 \mathrm{mmol})$ was added to a toluene solution $(10 \mathrm{~mL})$ of compound $1(0.035 \mathrm{~g}, 0.047$ $\mathrm{mol}$ ), and the mixture was stirred at room temperature for $20 \mathrm{~min}$ to give an orange solution. The solvent was then removed under vacuum, the residue was extracted with dichloromethane/petroleum ether (1/2), and the extracts chromatographed on alumina at $253 \mathrm{~K}$. Elution with dichloromethane/petroleum ether (1/1) gave a yellow fraction yielding, after removal of solvents, compound $\mathbf{3}$ as a yellow microcrystalline solid (0.026 g, 51\%). Anal. Calcd for $\mathrm{C}_{40} \mathrm{H}_{37} \mathrm{~N}_{2} \mathrm{O}_{2} \mathrm{PSnW}_{2}$ : C, 43.87; H, 3.41; N, 2.56. Found: $\mathrm{C}, 44.20 ; \mathrm{H}, 3.39 ; \mathrm{N}, 2.61 .{ }^{1} \mathrm{H}$ NMR (300.13 MHz, $\left.\mathrm{CD}_{2} \mathrm{Cl}_{2}\right): \delta 7.95-6.55$ (m, 25H, Ph), $5.32,4.98(2 \mathrm{~s}, 2 \times 5 \mathrm{H}, \mathrm{Cp}),-0.52\left(\mathrm{dd}, J_{\mathrm{HP}}=13, J_{\mathrm{HH}}=3, J_{\mathrm{HW}}=68, J_{\mathrm{H} 119 \mathrm{Sn}} \approx J_{\mathrm{H} 117 \mathrm{Sn}}=\right.$ $81,1 \mathrm{H}, \mathrm{WH}),-5.23\left(\mathrm{dd}, J_{\mathrm{HP}}=26, J_{\mathrm{HH}}=3, J_{\mathrm{HW}}=55,50, J_{\mathrm{H} 119 \mathrm{Sn}}=100, J_{\mathrm{H} 117 \mathrm{Sn}}=96,1 \mathrm{H}\right.$, $\mu-\mathrm{H})$.

Preparation of $\left[\mathbf{W}_{2} \mathbf{C p}_{2}(\mu-\mathbf{S P h})(\mu-\mathbf{P P h})(\mathbf{N O})_{2}\right](4)$. Neat HSPh $(8 \mu \mathrm{L}, 0.078 \mathrm{mmol})$ was added to a toluene solution $(10 \mathrm{~mL})$ of compound $1(0.025 \mathrm{~g}, 0.034 \mathrm{~mol})$, and the mixture was stirred at room temperature for $10 \mathrm{~min}$ to give a yellow solution. The solvent was then removed under vacuum, the residue was extracted with dichloromethane/petroleum ether (1/2), and the extracts chromatographed on alumina at $288 \mathrm{~K}$. Elution with dichloromethane/petroleum ether (1/1) gave a yellow fraction yielding, after removal of solvents, compound $\mathbf{4}$ as a yellow microcrystalline solid (0.020 g, 69\%). Anal. Calcd for $\mathrm{C}_{28} \mathrm{H}_{25} \mathrm{~N}_{2} \mathrm{O}_{2} \mathrm{PSW}_{2}$ : C, 39.46; H, 2.96; N, 3.29; S, 3.76. Found: C, 39.74; H, 2.96; N, 3.24; S, 3.11. ${ }^{1} \mathrm{H}$ NMR (300.13 MHz, $\left.\mathrm{CD}_{2} \mathrm{Cl}_{2}\right): \delta 7.80-7.23$ (m, 15H, Ph), 5.48, 5.03 (2s, 2 x 5H, Cp).

Preparation of $\left[\mathrm{W}_{2} \mathrm{Cp}_{2}\left\{\mu-\mathrm{OCH}_{2}(p-\right.\right.$ tol $\left.\left.)\right\}\left(\mu-\mathrm{PPh}_{2}\right)(\mathrm{NO})_{2}\right]$ (5). A large excess of ( $p$ tol $) \mathrm{C}(\mathrm{O}) \mathrm{H}(120 \mu \mathrm{L}, 1.018 \mathrm{mmol})$ was added to a toluene solution $(10 \mathrm{~mL})$ of compound $1(0.030 \mathrm{~g}, 0.040 \mathrm{~mol})$, and the mixture was refluxed for $15 \mathrm{~min}$ to give an orange 
solution. The solvent was then removed under vacuum, the residue was extracted with dichloromethane/petroleum ether (1/2), and the extracts were chromatographed on alumina at $288 \mathrm{~K}$. Elution with dichloromethane/petroleum ether (2/1) gave a yellow fraction yielding, after removal of solvents, compound $\mathbf{5}$ as a yellow microcrystalline solid (0.022 g, 64\%). Anal. Calcd for $\mathrm{C}_{30} \mathrm{H}_{29} \mathrm{~N}_{2} \mathrm{O}_{3} \mathrm{PW}_{2}$ : C, 41.69; H, 3.38; N, 3.24. Found: $\mathrm{C}, 41.44 ; \mathrm{H}, 2.93 ; \mathrm{N}, 3.33 .{ }^{1} \mathrm{H}$ NMR $\left(300.13 \mathrm{MHz}, \mathrm{CD}_{2} \mathrm{Cl}_{2}\right): \delta 7.70-7.30(\mathrm{~m}$, $14 \mathrm{H}, \mathrm{Ph}$ and $\left.\mathrm{C}_{6} \mathrm{H}_{4}\right), 5.44\left(\mathrm{~d}, J_{\mathrm{HH}}=11,1 \mathrm{H}, \mathrm{OCH}_{2}\right), 5.284,5.280(2 \mathrm{~s}, 2 \mathrm{x} 5 \mathrm{H}, \mathrm{Cp}), 4.86$ $\left(\mathrm{d}, J_{\mathrm{HH}}=11,1 \mathrm{H}, \mathrm{OCH}_{2}\right), 2.46(\mathrm{~s}, 3 \mathrm{H}, \mathrm{Me})$.

Preparation of $\left[\mathrm{W}_{2} \mathrm{Cp}_{2}\left(\mu-\kappa^{1}: \eta^{2}-\mathrm{HCN}^{t} \mathrm{Bu}\right)\left(\mu-\mathrm{PPh}_{2}\right)(\mathrm{NO})_{2}\right]$ (6). Neat $\mathrm{CN}^{t} \mathrm{Bu}(12 \mu \mathrm{L}$, $0.106 \mathrm{mmol})$ was added to a dichloromethane solution $(10 \mathrm{~mL})$ of compound $1(0.030$ $\mathrm{g}, 0.040 \mathrm{mmol}$ ), and the mixture was stirred at room temperature for $15 \mathrm{~min}$ to give a yellow solution. The solvent was then removed under vacuum, the residue was extracted with dichloromethane/petroleum ether (1/2), and the extracts were chromatographed on alumina at $288 \mathrm{~K}$. Elution with dichloromethane/petroleum ether (2/1) gave a yellow fraction yielding, after removal of solvents, a yellow solid shown (by NMR) to contain a ca. 3:1 mixture of isomers 6 and $7(0.020 \mathrm{~g}, 60 \%)$. Pure isomer 6 could be obtained through fractional crystallization of the above solid from dichloromethane/toluene/petroleum ether mixtures. The crystals of $\mathbf{6}$ used in the X-ray diffraction study were grown through the slow diffusion of layers of toluene and petroleum ether into a concentrated dichloromethane solution of the complex at $253 \mathrm{~K}$. Anal. Calcd for $\mathrm{C}_{27} \mathrm{H}_{30} \mathrm{~N}_{3} \mathrm{O}_{2} \mathrm{PW}_{2}$ : C, 39.20; H, 3.66; N, 5.08. Found: C, 38.98; H, 3.40; $\mathrm{N}, 4.80 .{ }^{1} \mathrm{H}$ NMR (300.13 MHz, $\left.\mathrm{CD}_{2} \mathrm{Cl}_{2}\right): \delta 10.02\left(\mathrm{~d}, J_{\mathrm{PH}}=1,1 \mathrm{H}, \mathrm{CH}\right), 7.90-7.00(\mathrm{~m}$, $10 \mathrm{H}, \mathrm{Ph}), 5.64\left(\mathrm{~d}, J_{\mathrm{PH}}=1,5 \mathrm{H}, \mathrm{Cp}\right), 5.53(\mathrm{~s}, 5 \mathrm{H}, \mathrm{Cp}), 1.43\left(\mathrm{~s}, 9 \mathrm{H},{ }^{t} \mathrm{Bu}\right) .{ }^{13} \mathrm{C}\left\{{ }^{1} \mathrm{H}\right\} \mathrm{NMR}$ $\left(75.46 \mathrm{MHz}, \mathrm{CD}_{2} \mathrm{Cl}_{2}\right): \delta 198.4(\mathrm{~s}, \mathrm{CH}), 142.1\left[\mathrm{~d}, J_{\mathrm{CP}}=45, \mathrm{C}^{1}(\mathrm{Ph})\right], 137.4\left[\mathrm{~d}, J_{\mathrm{CP}}=50\right.$, $\left.\mathrm{C}^{1}(\mathrm{Ph})\right], 135.9,133.1$ [2d, $\left.J_{\mathrm{CP}}=11, \mathrm{C}^{2}(\mathrm{Ph})\right], 130.7,129.2\left[2 \mathrm{~d}, J_{\mathrm{CP}}=3, \mathrm{C}^{4}(\mathrm{Ph})\right], 129.5$, $128.5\left[2 \mathrm{~d}, J_{\mathrm{CP}}=12, \mathrm{C}^{3}(\mathrm{Ph})\right], 101.8,97.1(2 \mathrm{~s}, \mathrm{Cp}), 66.3\left[\mathrm{~s}, \mathrm{C}^{1}\left({ }^{t} \mathrm{Bu}\right)\right], 31.5\left[\mathrm{~s}, \mathrm{C}^{2}\left({ }^{t} \mathrm{Bu}\right)\right]$.

Preparation of $\left[\mathrm{W}_{2} \mathrm{Cp}_{2}\left\{\mu-\mathrm{C}\left(\mathrm{NH}^{t} \mathrm{Bu}\right)\right\}\left(\mu-\mathrm{PPh}_{2}\right)(\mathrm{NO})_{2}\right]$ (7). A dichloromethane solution $(10 \mathrm{~mL})$ of $\mathrm{CN}^{t} \mathrm{Bu}(12 \mu \mathrm{L}, 0.106 \mathrm{mmol})$ was added dropwise to a stirred dichloromethane solution $(10 \mathrm{~mL})$ of compound $1(0.030 \mathrm{~g}, 0.040 \mathrm{mmol})$ at $273 \mathrm{~K}$, and the mixture was further stirred at this temperature for $10 \mathrm{~min}$ to give an orange solution. Workup as described for $\mathbf{6}$ yielded an orange solid shown (by NMR) to contain a ca. 1:3 mixture of isomers 6 and $7(0.020 \mathrm{~g}, 60 \%)$. Pure isomer 7 could be obtained from fractional crystallization of the above solid from dichloromethane/toluene/petroleum ether mixtures. The crystals of $\mathbf{7}$ used in the X-ray diffraction study were grown as described for 6. Anal. Calcd for $\mathrm{C}_{27} \mathrm{H}_{30} \mathrm{~N}_{3} \mathrm{O}_{2} \mathrm{PW}_{2}$ : C, 39.20; H, 3.66; N, 5.08. Found: C, 38.85; H, 4.10; N, 4.54. ${ }^{1} \mathrm{H}$ NMR (300.13 MHz, $\mathrm{CD}_{2} \mathrm{Cl}_{2}$ ): $\delta 9.99$ (s, $\left.1 \mathrm{H}, \mathrm{NH}\right), 7.90-7.20$ $(\mathrm{m}, 10 \mathrm{H}, \mathrm{Ph}), 5.26,5.19\left(2 \mathrm{~d}, J_{\mathrm{PH}}=1,2 \times 5 \mathrm{H}, \mathrm{Cp}\right), 1.66\left(\mathrm{~s}, 9 \mathrm{H},{ }^{t} \mathrm{Bu}\right) .{ }^{13} \mathrm{C}\left\{{ }^{1} \mathrm{H}\right\} \mathrm{NMR}$ (75.46 MHz, $\mathrm{CD}_{2} \mathrm{Cl}_{2}$ ): $\delta 336.0(\mathrm{~s}, \mu-\mathrm{C}), 145.6,141.9$ [2d, $\left.J_{\mathrm{CP}}=44, \mathrm{C}^{1}(\mathrm{Ph})\right], 135.5$, 
$134.1\left[2 \mathrm{~d}, J_{\mathrm{CP}}=11, \mathrm{C}^{2}(\mathrm{Ph})\right], 129.2\left[\mathrm{~d}, J_{\mathrm{CP}}=2, \mathrm{C}^{4}(\mathrm{Ph})\right], 128.6\left[\mathrm{~d}, J_{\mathrm{CP}}=3, \mathrm{C}^{4}(\mathrm{Ph})\right]$, 128.6, $128.3\left[2 \mathrm{~d}, J_{\mathrm{CP}}=11, \mathrm{C}^{3}(\mathrm{Ph})\right], 95.7,95.6(2 \mathrm{~s}, \mathrm{Cp}), 62.6\left[\mathrm{~s}, \mathrm{C}^{1}\left({ }^{t} \mathrm{Bu}\right)\right], 30.9[\mathrm{~s}$, $\left.\mathrm{C}^{2}\left({ }^{t} \mathrm{Bu}\right)\right]$.

Preparation of $\left[\mathrm{W}_{2} \mathrm{Cp}_{2}\left(\mu-\kappa^{1}: \eta^{2}-\mathrm{CH}_{3}\right)\left(\boldsymbol{\mu}-\mathbf{P P h}_{2}\right)(\mathrm{NO})_{2}\right]$ (8). Excess $\mathrm{CH}_{2} \mathrm{~N}_{2}$ (1 mL of a ca. $0.7 \mathrm{M}$ solution in diethyl ether, $0.7 \mathrm{mmol})$ was added to a toluene solution $(10 \mathrm{~mL})$ of compound 1 ( $0.030 \mathrm{~g}, 0.040 \mathrm{~mol})$, and the mixture was stirred at room temperature for $10 \mathrm{~min}$ to give a yellow solution. After removal of volatiles under vacuum, the residue was dissolved in toluene, the solution filtered and the solvent again removed from the filtrate, to give a residue which was washed with petroleum ether $(5 \mathrm{~mL})$ to yield compound 8 as a yellow solid $(0.021 \mathrm{~g}, 69 \%)$. Anal. Calcd for $\mathrm{C}_{23} \mathrm{H}_{23} \mathrm{~N}_{2} \mathrm{O}_{2} \mathrm{PW}_{2}$ : C, 36.44; H, 3.06; N, 3.70. Found: C, 36.07; H, 2.73; N, 3.59. ${ }^{1} \mathrm{H}$ NMR (300.13 MHz, $\left.\mathrm{CD}_{2} \mathrm{Cl}_{2}\right): \delta 7.95-7.20(\mathrm{~m}, 10 \mathrm{H}, \mathrm{Ph}), 5.35(\mathrm{~s}, 10 \mathrm{H}, \mathrm{Cp}),-2.09\left(\mathrm{~s}, J_{\mathrm{HC}}=113, J_{\mathrm{HW}}=8,3 \mathrm{H}\right.$, $\left.\mu-\mathrm{CH}_{3}\right) .{ }^{13} \mathrm{C}\left\{{ }^{1} \mathrm{H}\right\}$ NMR $\left(75.46 \mathrm{MHz}, \mathrm{CD}_{2} \mathrm{Cl}_{2}\right): \delta 143.4\left[\mathrm{~d}, J_{\mathrm{CP}}=50, \mathrm{C}^{1}(\mathrm{Ph})\right], 134.6[\mathrm{~d}$, $\left.J_{\mathrm{CP}}=11, \mathrm{C}^{2}(\mathrm{Ph})\right], 129.5\left[\mathrm{~d}, J_{\mathrm{CP}}=2, \mathrm{C}^{4}(\mathrm{Ph})\right], 128.7\left[\mathrm{~d}, J_{\mathrm{CP}}=11, \mathrm{C}^{3}(\mathrm{Ph})\right], 95.8(\mathrm{~s}, \mathrm{Cp})$, $5.8\left(\mathrm{~s}, J_{\mathrm{CW}}=71, \mu-\mathrm{CH}_{3}\right)$.

Preparation of $\left[\mathrm{W}_{2} \mathrm{Cp}_{2}\left\{\mu-\mathrm{NH}\left(\mathrm{NCHSiMe}_{3}\right)\right\}\left(\mu-\mathrm{PPh}_{2}\right)(\mathrm{NO})_{2}\right]$ (9). A slight excess of $\mathrm{N}_{2} \mathrm{CH}\left(\mathrm{SiMe}_{3}\right)$ (30 $\mu \mathrm{L}$ of a $2 \mathrm{M}$ solution in hexanes, $0.06 \mathrm{mmol}$ ) was added to a dichloromethane solution $(10 \mathrm{~mL})$ of compound $1(0.040 \mathrm{~g}, 0.054 \mathrm{~mol})$, and the mixture was stirred at room temperature for $10 \mathrm{~min}$ to give a yellow-orange solution. The solvent was then removed under vacuum, and the residue was washed with petroleum ether $(5 \mathrm{~mL})$ to yield compound 9 as a yellow solid $(0.028 \mathrm{~g}, 60 \%)$. The crystals of 9 used in the X-ray diffraction study were grown as described for 6. Anal. Calcd for $\mathrm{C}_{26} \mathrm{H}_{31} \mathrm{~N}_{4} \mathrm{O}_{2} \mathrm{PSiW}$ : C, 36.38; H, 3.64; N, 6.53. Found: C, 36.06; H, 3.43; N, 5.97. ${ }^{1} \mathrm{H}$ NMR (300.13 MHz, $\mathrm{CD}_{2} \mathrm{Cl}_{2}$ ): $\delta 8.23$ (s, br, 1H, NH), 8.11 (s, 1H, CH), 8.00-7.20 (m, 10H, Ph), 5.39 (d, $\left.J_{\mathrm{PH}}=1,10 \mathrm{H}, \mathrm{Cp}\right), 0.25$ (s, 9H, $\mathrm{SiMe}_{3}$ ).

Preparation of $\left[\mathrm{W}_{2} \mathrm{Cp}_{2}\{\mu-\mathrm{N}(\mathrm{NMe})\}\left(\mu-\mathrm{PPh}_{2}\right)(\mathrm{NO})_{2}\right]$ (10). The crude compound 9 , prepared as described above, was dissolved with dichloromethane/petroleum ether (1/2), and the solution was chromatographed on alumina at $288 \mathrm{~K}$. Elution with dichloromethane/petroleum ether (2/1) gave a red fraction yielding, after removal of solvents, compound $\mathbf{1 0}$ as a red solid $(0.015 \mathrm{~g}, 35 \%$ based on $\mathbf{1})$. The crystals of $\mathbf{1 0}$ used in the X-ray diffraction study were grown as described for 6. Anal. Calcd for $\mathrm{C}_{23} \mathrm{H}_{23} \mathrm{~N}_{4} \mathrm{O}_{2} \mathrm{PW}_{2}$ : C, 35.14; H, 2.95; N, 7.13. Found: C, 35.12; H, 3.18; N, 6.36. ${ }^{1} \mathrm{H}$ NMR (300.13 MHz, $\left.\mathrm{CD}_{2} \mathrm{Cl}_{2}\right): \delta 7.90-7.25(\mathrm{~m}, 10 \mathrm{H}, \mathrm{Ph}), 5.42,5.41\left(2 \mathrm{~d}, J_{\mathrm{PH}}=1,2 \times 5 \mathrm{H}\right.$, Cp), 4.29 (s, 3H, NMe).

X-ray Structure Determination of Compounds 6, 9 and 10. Data collection for these compounds was carried out at $100 \mathrm{~K}$ on a Kappa-Appex-II Bruker diffractometer using graphite-monochromated MoK $\alpha$ radiation. The software $\mathrm{APEX}^{47}$ was used for collecting frames with a $\omega / \phi$ scans measurement method. Data reduction was carried out 
with the SAINT software, ${ }^{48}$ and a multi-scan absorption correction was applied with SADABS ${ }^{49}$ Using the program suite WINGX, ${ }^{50}$ the structures were solved by Patterson interpretation and phase expansion using SHELXL2016, and refined with full-matrix least squares on $F^{2}$ using SHELXL2016, ${ }^{51}$ to give the residuals collected in Table S4 (see the SI). In general, all non-hydrogen atoms were refined anisotropically, except those involved in disorder, which were refined isotropically to prevent their temperature factors from becoming non-positive definite, and all hydrogen atoms were geometrically placed and refined using a riding model. Compound $\mathbf{6}$ crystallized with a toluene molecule, and the atom H1 was located in the Fourier maps and refined isotropically. Compound $\mathbf{9}$ also crystallized with a toluene molecule, now disordered over two sites, successfully refined with 0.6/0.4 occupancies, and the atoms H1 and $\mathrm{H} 3 \mathrm{~B}$ were located and refined isotropically; however, restraints on the $\mathrm{C} 1-\mathrm{H} 1$ bond and the $\mathrm{C}-\mathrm{C}$ lengths within the toluene molecule had to be applied to achieve a satisfactory model.

X-ray Structure Determination of Compound 7. Data collection was carried out at $150 \mathrm{~K}$ on an Oxford Diffraction Xcalibur Nova single crystal diffractometer, using Cu$\mathrm{K}_{\alpha}$ radiation. Images were collected at a $62 \mathrm{~mm}$ fixed crystal-detector distance, using the oscillation method and 1.5-3.0 s exposure time per image. Data collection strategy was calculated with the program CrysAlis Pro $C C D,{ }^{52}$ and data reduction and cell refinement were performed with the program CrysAlis Pro RED. ${ }^{52}$ An empirical absorption correction was applied using the SCALE3 ABSPACK algorithm as implemented in the latter program. Structure solution and refinements were generally performed as described above, to give the residuals collected in Table S4 (see the SI). The carbon atoms $\mathrm{C}(11), \mathrm{C}(13)$ and $\mathrm{C}(15)$ were refined anisotropically in combination with the instructions SIMU and DELU, and the N-bound $\mathrm{H} 3$ atom was located in the Fourier maps and refined isotropically with a restraint on the corresponding $\mathrm{N}-\mathrm{H}$ bond length.

Computational Details. All DFT computations were carried out using the GAUSSIAN03 package, ${ }^{53}$ in which the hybrid method B3LYP was used with the Becke three-parameter exchange functional ${ }^{54}$ and the Lee-Yang-Parr correlation functional. ${ }^{55}$ A pruned numerical integration grid $(99,590)$ was used for all the calculations via the keyword Int=Ultrafine. Effective core potentials and their associated double- $\zeta$ LANL2DZ basis set were used for the metal atoms. ${ }^{56}$ The light elements ( $\mathrm{P}, \mathrm{O}, \mathrm{C}, \mathrm{N}$ and $\mathrm{H}$ ) were described with the $6-31 \mathrm{G}^{*}$ basis. ${ }^{57}$ Geometry optimizations were performed under no symmetry restrictions, and frequency analyses were performed for all the stationary points to ensure that minimum structures with no imaginary frequencies were achieved. NMR shielding contributions and coupling constants were calculated using the gauge-including atomic orbitals (GIAO) method, ${ }^{58}$ in combination 
with the LANL2DZ basis set for the $\mathrm{W}$ atoms and the IGLO-II basis set of Kutzelnigg and co-workers for the remaining atoms. ${ }^{59}$ Molecular graphics and vibrational modes were visualized using the Molekel program. ${ }^{60}$

Supporting Information. A CIF file containing full crystallographic data for compounds 6, 7, 9 and 10 (CCDC 1585985-1585988), a PDF file containing results of DFT calculations (structures, energies, and NMR data), and an XYZ file including the Cartesian coordinates for all computed species. This material is available free of charge via the Internet at http://pubs.acs.org.

Author Information. Corresponding authors: E-mail: garciavdaniel@uniovi.es (D. G. V.), mara@uniovi.es (M. A. R).

Acknowledgment. We thank the Gobierno del Principado de Asturias for a grant (to A. T.) and financial support (Project GRUPIN14-011), the MINECO of Spain and FEDER for financial support (Project CTQ2015-63726-P), and the CMC and X-Ray units of the Universidad de Oviedo for access to computing facilities and acquisition of diffraction data, respectively. 


\section{References}

1. (a) Richter-Addo, G. B.; Legzdins, P. Metal Nitrosyls; Oxford University Press: Oxford, U. K., 1992. (b) Mingos, D. M. P. (Ed.), Nitrosyl Complexes in Inorganic Chemistry, Biochemistry and Medicine; Struct. Bond. 2014, Vols 153 and 154.

2. For some recent reviews, see: (a) Hunt, A. P.; Lehnert, N. Heme-Nitrosyls: Electronic Structure Implications for Function in Biology. Acc. Chem. Res. 2015, 48, 2117-2125. (b) Tsai, M. L.; Tsou, C. C.; Liaw, W. F. Dinitrosyl Iron Complexes (DNICs): From Biomimetic Synthesis and Spectroscopic Characterization toward Unveiling the Biological and Cataytic Roles of DNICs. Acc. Chem. Res. 2015, 48, 1184-1193. (c) Tram, C. T.; Skodje, K. M.; Kim, E. Monomeric Dinitrosyl Iron Complexes: Synthesis and Reactivity. Progr. Inorg. Chem. 2014, 59, 339-380. (d) Doctorovich, F.; Bikiel, D. E.; Pellegrino, J.; Suarez, S. A.; Marti, M. A. Reactions of $\mathrm{HNO}$ with Metal Porphyrins: Underscoring the Biological relevance of HNO. Acc. Chem. Res. 2014, 47, 2907-2916. (e) Franke, A.; van Eldik, R. Factors that Determine the Mechanism of NO Activation by Metal Complexes of Biological and Environmental Relevance. Eur. J. Inorg. Chem. 2013, 460-480. (f) Berto, T. C.; Speelman, A. M.; Zheng, S.; Lehnert, N. Mono- and dinuclear non-heme ironnitrosyl complexes: Models for key intermediates in bacterial nitric oxide reductases. Coord. Chem. Rev. 2013, 257, 244-259.

3. Xiang, H. J.; Guo, M.; Liu, J. G. Transition-Metal Nitrosyls for Photocontrolled Nitric Oxide Delivery. Eur. J. Inorg. Chem. 2017, 12, 1586-1595.

4. (a) Reduction of Nitrogen Oxide Emissions; Ozkan, U. S.; Agarwal, S. K.; Marcelin, G., Eds.; American Chemical Society: Washington, DC, 1995. (b) Environmental Catalysis; Armor, J. M., Ed.; American Chemical Society: Washington, DC, 1994. (c) Catalytic Control of Air Pollution; Silver, R. G.; Sawyer, J. E.; Summers, J. C., Eds.; American Chemical Society: Washington, DC 1992. (d) Energy and the Environment; Dunderdale, J., Ed.; Royal Society of Chemistry: Cambridge, U. K., 1990. (e) Pollution: Causes, Effects and Control; Harrison, R. M., Ed.; Royal Society of Chemistry: Cambridge, U. K., 1990.

5. (a) Liu, F.; Yu, Y.; He, H. Environmentally-benign catalysts for the selective catalytic reduction of $\mathrm{NO}_{\mathrm{x}}$ from diesel engines: structure-activity relationships and reaction mechanism aspects. Chem. Commun. 2014, 50, 8445-8463. (b) Granger, P.; Parvulescu, V. I. Catalytic $\mathrm{NO}_{\mathrm{x}}$ Abatement Systems for Mobile Sources: From Three-Way to Lean Burn after-Treatment Technologies. Chem. Rev. 2011, 111, 3155-3207. (c) Basu, S. Chemical and biochemical processes for $\mathrm{NO}_{\mathrm{x}}$ control from combustion off-gases. Chem. Eng. Commun. 2007, 194, 1374-1395. (d) Javed, M. T.; Irfan, N.; Gibbs, B. M. Control of combustion-generated nitrogen oxides by selective non-catalytic reduction. J. Environm. Manag. 2007, 83, 251-289. (e) 
Wallington, T. J.; Kaiser, E. W.; Farrell, J. T. Automotive fuels and internal combustion engines: a chemical perspective. Chem. Soc. Rev. 2006, 35, 335-347.

6. Alvarez, M. A.; García, M. E.; García-Vivó, D.; Ruiz, M. A.; Toyos, A. The Doubly-Bonded Ditungsten Anion $\left[\mathrm{W}_{2} \mathrm{Cp}_{2}\left(\mu-\mathrm{PPh}_{2}\right)(\mathrm{NO})_{2}\right]^{-}$: An Entry to the Chemistry of Unsaturated Nitrosyl Complexes. Dalton Trans. 2016, 45, 1330013303.

7. We have adopted a "half-electron" counting convention for complexes displaying bridging hydrides, so compound $\mathbf{1}$ is regarded as having a $\mathrm{W}=\mathrm{W}$ bond (but see our DFT description of such a bond). Other authors, however, recommend the adoption of a "half-arrow" convention (see Green M. L. H.; Parkin, G. Struct. Bond. 2017, 117, 79-140 and references therein). Under such convention, however, the 32electron hydride 1 should be assimilated to the 34-electron complexes $\left[\mathrm{W}_{2} \mathrm{Cp}_{2}(\mu\right.$ $\left.\mathrm{X})\left(\mu-\mathrm{PPh}_{2}\right)(\mathrm{NO})_{2}\right]\left(\mathrm{X}=\mathrm{I}, \mathrm{SR}, \mathrm{PR}_{2}, \mathrm{CNHR}\right.$, etc), a relationship which we consider of little use to interpret the strong differences separating the structure, spectroscopic properties, and reactivity of all these molecules.

8. (a) Legzdins, P.; Martin, J. T.; Oxley, J. C. New Organometallic Hydrido Nitrosyl Complexes of Tungsten. Organometallics 1985, 4, 1263-1271. (b) Legzdins, P.; Martin, J. T.; Einstein, F. W. B.; Willis, A. C. Proton NMR Spectroscopic Criteria for Elucidating the Structures of Bimetallic Organotungsten Hydrides in Solutions. Crystal and Molecular Structures of $\left[\mathrm{CpW}(\mathrm{NO}) \mathrm{H}_{2}(\mu-\mathrm{H})_{2}\right.$. J. Am. Chem. Soc. 1986, 108, 7971-7981. (c) Legzdins, P.; Martin, J. T.; Einstein, F. W. B.; Jones, R. H. New Types of Remarkably Stable Alkyl Hydride Complexes of Tungsten. Organometallics 1987, 6, 1826-1827. (d) Lin, X.; Legzdins, P.; Buschhaus, M. S. A. Parallel Transformations of Cyclohexene Mediated by the $\mathrm{Cp}^{*} \mathrm{~W}(\mathrm{NO})$ Fragment. J. Am. Chem. Soc. 2005, 127, 6928-6929.

9. We have recently reported the use of compound $\mathbf{1}$ also as a building block to prepare heterometallic clusters bearing both $\mathrm{CO}$ and NO ligands. See Alvarez, M. A.; García, M. E.; García-Vivó, D.; Ruiz, M. A.; Toyos, A. Structure and Dynamics of Heterometallic Clusters Derived from Addition of Metal Carbonyl Fragments to the Unsaturated Hydride $\left[\mathrm{W}_{2} \mathrm{Cp}_{2}(\mu-\mathrm{H})\left(\mu-\mathrm{PPh}_{2}\right)(\mathrm{NO})_{2}\right]$. Dalton Trans. 2017, 46, 15317-15329.

10. (a) Raithby, P. R.; Johnson, A. L. in Comprehensive Organometallic Chemistry, 3rd ed.; Mingos, D. M. P.; Crabtree, R. H., Eds.; Elsevier: Oxford, U. K., 2007; Vol. 6 (Bruce, M., Ed.), Chapters 18 and 19. (b) Smith, A. K. in Comprehensive Organometallic Chemistry, 2nd ed.; Abel, E. W.; Stone, F. G. A.; Wilkinson, G., Eds.; Pergamon: Oxford, U. K., 1995; Vol. 7, Chapter 13. (c) Deeming, A. J. Triosmium Clusters. Adv. Organomet. Chem. 1986, 26, 1-96. (d) Burgess, K. 
Reactions of Triosmium Clusters with Organic Compounds. Polyhedron 1984, 3, 1175-1225.

11. (a) Bennett, M. J.; Graham, W. A. G.; Hoyano, J. K.; Hutcheon, W. L. Synthesis and X-Ray Structure of Di- $\mu$-hydrido-octacarbonyl dirhenium. J. Am. Chem. Soc. 1972, 94, 6232-6233. (b) D'Alfonso, G. Anionic Oligomerization as a Route to Chain Clusters. Chem. Eur. J. 2000, 6, 209-215. (c) Huang, S. H.; Watson, W. H.; Carrano, C. J.; Wang, X.; Richmond, M. G. Directed Synthesis of the Triangular Mixed-Metal Cluster $\mathrm{H}_{2} \mathrm{RhRe}_{2} \mathrm{Cp}^{*}(\mathrm{CO})_{9}$ : Ligand Fluxionality and Facile Cluster Fragmentation in the Presence of CO, Halogenated Solvents, and Thiols. Organometallics 2010, 29, 61-75, and references therein.

12. (a) Alvarez, M. A.; Alvarez, M. P.; Carreño, R.; Ruiz, M. A.; Bois, C. Reactivity of the unsaturated manganese dihydrides $\left[\mathrm{Mn}_{2}(\mu-\mathrm{H})_{2}(\mathrm{CO})_{6}\left(\mu-\mathrm{L}_{2}\right)\right]\left[\mathrm{L}_{2}=\right.$ (EtO) $)_{2} \mathrm{POP}(\mathrm{OEt})_{2}, \mathrm{Ph}_{2} \mathrm{PCH}_{2} \mathrm{PPh}_{2}, \mathrm{Me}_{2} \mathrm{PCH}_{2} \mathrm{PMe}_{2}$ towards silicon and tin hydrides. J. Organomet. Chem. 2011, 696, 1736-1748. (b) García, M. E.; Melón, S.; Ruiz, M. A.; Marchiò, L.; Tiricpicchio, A. Nitrosyl derivatives of the unsaturated dihydrides $\left[\mathrm{Mn}_{2}(\mu-\mathrm{H})_{2}(\mathrm{CO})_{6}\left(\mu-\mathrm{L}_{2}\right)\right]\left(\mathrm{L}_{2}=\mathrm{Ph}_{2} \mathrm{PCH}_{2} \mathrm{PPh}_{2}\right.$, $\left.(\mathrm{EtO})_{2} \mathrm{POP}(\mathrm{OEt})_{2}\right)$. J. Organomet Chem. 2011, 696, 559-567. (c) García-Alonso, F. J.; García, M.; Liu, X.-Y.; Oliveira, A.; Ruiz, M. A.; Riera, V.; Bois, C. Reactivity of the unsaturated manganese dihydrides $\left[\mathrm{Mn}_{2}(\mu-\mathrm{H})_{2}(\mathrm{CO})_{6}\left(\mu-\mathrm{L}_{2}\right)\right] \quad\left(\mathrm{L}_{2}=\mathrm{Ph}_{2} \mathrm{PCH}_{2} \mathrm{PPh}_{2}\right.$ or $\left.(\mathrm{EtO})_{2} \mathrm{POP}(\mathrm{OEt})_{2}\right)$ towards small molecules. J. Organomet. Chem. 1996, 511, 93102. (d) Carreño, R.; Riera, V.; Ruiz, M. A.; Lanfranchi, M.; Tiripicchio, A.; Tiripicchio-Camellini, M. Reactivity of $\left[\mathrm{Mn}_{2}(\mu-\mathrm{H})_{2}(\mathrm{CO})_{6}(\mu\right.$-tedip)] (tedip = $\left.(\mathrm{EtO})_{2} \mathrm{POP}(\mathrm{OEt})_{2}\right)$ with Group 11 Alkynyl Compounds. X-ray Structures of $\left[\mathrm{Ag}_{2} \mathrm{Mn}_{4}(\mu \text {-H })_{6}(\mathrm{CO})_{12}(\mu \text {-tedip })_{2}\right] \quad$ and $\quad\left[\mathrm{AuMn}_{4}(\mu \text {-H })_{5}(\mathrm{CO})_{12}(\mu \text {-tedip })_{2}\right]$. Organometallics 1994, 13, 993-1004, and references therein. (e) Carreño, R.; Riera, V.; Ruiz, M. A.; Bois, C.; Jeannin, Y. Reactivity of the unsaturated dihydrides $\left[\mathrm{Mn}_{2}(\mu-\mathrm{H})_{2}(\mathrm{CO})_{6}\left(\mu-\mathrm{L}_{2}\right)\right]\left(\mathrm{L}_{2}=\mathrm{Ph}_{2} \mathrm{PCH}_{2} \mathrm{PPh}_{2},(\mathrm{EtO})_{2} \mathrm{POP}(\mathrm{OEt})_{2}\right)$ toward boron hydrides. X-ray crystal structure of $\left[\mathrm{Mn}_{2}\left(\mu-\mathrm{BH}_{4}\right)(\mu-\mathrm{H})(\mathrm{CO})_{5}\left(\mu-\mathrm{Ph}_{2} \mathrm{PCH}_{2} \mathrm{PPh}_{2}\right)\right]$, a molecule displaying a novel coordination mode of the tetrahydroborate ligand. Organometallics 1993, 12, 1946-1953, and references therein.

13. García-Vivó, D.; Ramos, A.; Ruiz, M. A. Cyclopentadienyl and related complexes of the group 6 elements having metal-metal triple bonds: synthesis, structure, bonding and reactivity. Coord. Chem. Rev. 2013, 257, 2143-2191.

14. (a) Alvarez, M. A.; García, M. E.; Ruiz, M. A.; Toyos, A.; Vega, M. F. Heterometallic Derivatives of the Unsaturated Ditungsten Hydride $\left[\mathrm{W}_{2}\left(\eta^{5}-\right.\right.$ $\left.\left.\mathrm{C}_{5} \mathrm{H}_{5}\right)_{2}(\mathrm{H})\left(\mu-\mathrm{PCy}_{2}\right)(\mathrm{CO})_{2}\right]$. Inorg. Chem. 2013, 52, 7068-7077. (b) Alvarez, M. A.; García, M. E.; García-Vivó; Ruiz, M. A.; Vega, M. F. Insertion, Rearrangement, and Coupling Processes in the Reactions of the Unsaturated Hydride Complex 
$\left[\mathrm{W}_{2}\left(\eta^{5}-\mathrm{C}_{5} \mathrm{H}_{5}\right)_{2}(\mathrm{H})\left(\mu-\mathrm{PCy}_{2}\right)(\mathrm{CO})_{2}\right]$ with Isocyanides. Organometallics 2013, 32, 4543-4555. (c) Alvarez, M. A.; García, M. E.; García-Vivó; Ruiz, M. A.; Vega, M. F. Hydride, Gold(I) and Related Derivatives of the Unsaturated Ditungsten Anion $\left[\mathrm{W}_{2} \mathrm{Cp}_{2}(\mu-\mathrm{PCy})(\mu-\mathrm{CO})_{2}\right]^{-}$. Dalton Trans. 2014, 43, 16044-16055. (d) Alvarez, M. A.; García, M. E.; García-Vivó; Ruiz, M. A.; Vega, M. F. Insertion and C-C Coupling Processes in Reactions of the Unsaturated Hydride $\left[\mathrm{W}_{2} \mathrm{Cp}_{2}(\mathrm{H})(\mu\right.$ $\left.\left.\mathrm{PCy}_{2}\right)(\mathrm{CO})_{2}\right]$ with Alkynes. Dalton Trans. 2016, 45, 5274-5289.

15. Jan, D. Y.; Workman, D. P.; Hsu, L. Y.; Krause, J. A.; Shore, S. G. Clusters Derived from the Hydroboration of $(\mu-\mathrm{H})_{2} \mathrm{Os}_{3}(\mathrm{CO})_{10}$ and Their Derivatives. Inorg. Chem. 1992, 31, 5123-5131.

16. (a) Alvarez, C. M.; Alvarez, M. A.; García, M. E.; Ramos, A.; Ruiz, M. A. Lanfranchi, M.; Tiripicchio, A. A Triply Bonded Dimolybdenum Hydride Complex with Acid, Base and Radical Activity. Organometallics 2005, 24, 7-9. (b) Alvarez, M. A.; García, M. E.; Ramos, A.; Ruiz, M. A. Dimolybdenum-Tin Derivatives of the Unsaturated Hydride $\left[\mathrm{Mo}_{2}\left(\eta^{5}-\mathrm{C}_{5} \mathrm{H}_{5}\right)_{2}(\mu-\mathrm{H})\left(\mu-\mathrm{PCy}_{2}\right)(\mathrm{CO})_{2}\right]$ and $\mathrm{HSnR}_{3}(\mathrm{R}=\mathrm{Ph}$, $\mathrm{Bu})$ : Bridging versus Terminal Coordination of the Triorganostannyl Group. Organometallics 2006, 25, 5374-5380.

17. Alvarez, M. A.; García, M. E.; Ruiz, M. A.; Vega, M. F. C-X Bond Formation and Cleavage in the Reactions of the Ditungsten Hydride Complex $\left[\mathrm{W}_{2}\left(\eta^{5}-\right.\right.$ $\left.\left.\mathrm{C}_{5} \mathrm{H}_{5}\right)_{2}(\mathrm{H})\left(\mu-\mathrm{PCy}_{2}\right)(\mathrm{CO})_{2}\right]$ with Small Molecules having Multiple $\mathrm{C}-\mathrm{X}$ bonds $(\mathrm{X}=$ C, N, O). Dalton Trans. 2011, 40, 8294-8297.

18. Jameson, C. J. In Phosphorus-31 NMR Spectroscopy in Stereochemical Analysis; Verkade, J. G., Quin, L. D., Eds.; VCH: Deerfield Beach, FL, 1987; Chapter 6.

19. A general trend established for ${ }^{2} J_{\mathrm{XY}}$ in complexes of the type $\left[\mathrm{MCpXYL}_{2}\right]$ is that $\left|J_{\text {cis }}\right|>\left|J_{\text {trans }}\right|$. See, for instance, reference 18 and Wrackmeyer, B.; Alt, H. G.; Maisel, H. E. Ein- und zwei-dimensionale Multikern NMR-Spektroskopie an den isomeren Halbsandwich-Komplexen cis- und trans-[( $\left.\left.\eta^{5}-\mathrm{C}_{5} \mathrm{H}_{5}\right) \mathrm{W}(\mathrm{CO})_{2}(\mathrm{H}) \mathrm{PMe}_{3}\right] . J$. Organomet. Chem. 1990, 399, 125-130.

20. Braterman, P. S. Metal Carbonyl Spectra; Academic Press: London, U. K., 1975.

21. De la Cruz, C.; Sheppard, N. A structure-based analysis of the vibrational spectra of nitrosyl ligands in transition-metal coordination complexes and clusters. Spectrochim. Acta, Part A 2011, 78, 7-28.

22. Alvarez, M. A.; García, M. E.; García-Vivó, D.; Melón, S.; Ruiz, M. A.; Toyos, A. Reactions of the Unsaturated Ditungsten Complexes $\left[\mathrm{W}_{2} \mathrm{Cp}_{2}\left(\mu-\mathrm{PPh}_{2}\right)_{2}(\mathrm{CO})_{\mathrm{x}}\right](\mathrm{x}=$ 1, 2) with Nitric Oxide. Stereoselective Carbonyl Displacement and OxygenTransfer Reactions of a Nitrite Ligand. Inorg. Chem. 2014, 53, 4739-4750.

23. (a) Adams, R. D.; Golembesky, N. M. Isocyanide insertion reactions and their role in the cluster-catalyzed hydrogenation of isocyanide molecules. J. Am. Chem. Soc. 
1979, 101, 2579-2587. (b) Fujita, K.; Nakaguma, H.; Hanasaka, F.; Yamaguchi, R. Synthesis of a DMPM and Hydrido-Bridged Diiridium Complex, [(Cp*Ir $)_{2}(\mu-$ dmpm $\left.)(\mu-\mathrm{H})_{2}\right][\mathrm{OTf}]_{2}$, and Its Reactivity toward Alkynes and Isocyanides. Organometallics 2002, 21, 3749-3757.

24. Alt, H. G.; Frister, T. Darstellung eines dimetallacyclopropen-komplexes durch insertion von methylisonitril in eine W-H-W-Brücke. J. Organomet. Chem. 1985, 293, C7-C9.

25. Alvarez, M. A.; García, M. E.; Martínez, M. E.; Ramos, A.; Ruiz, M. A. Migration and Insertion Processes in the Reactions of the Hydrocarbyl-Bridged Unsaturated Complexes $\left[\mathrm{Mo}_{2}\left(\eta^{5}-\mathrm{C}_{5} \mathrm{H}_{5}\right)_{2}(\mu-\mathrm{R})(\mu-\mathrm{PCy})(\mathrm{CO})_{2}\right]\left(\mathrm{R}=\mathrm{Me}, \mathrm{CH}_{2} \mathrm{Ph}, \mathrm{Ph}\right)$ with $\mathrm{CO}$ and NO. Organometallics 2009, 28, 6293-6307.

26. Alvarez, M. A.; García, M. E.; García-Vivó, D.; Ruiz, M. A.; Toyos, A. Mild N-O Bond Cleavage Reactions of a Pyramidalized Nitrosyl Ligand Bridging a Dimolybdenum Center. Inorg. Chem. 2015, 54, 10536-10538.

27. (a) Evans, W. J; Meadows, J. H.; Hunter, W. E.; Atwood, J. L. Organolanthanide and organoyttrium hydride chemistry. 4. Reaction of isocyanides with $\left[\left(\mathrm{C}_{5} \mathrm{H}_{4} \mathrm{R}\right)_{2} \mathrm{YH}(\mathrm{THF})\right]_{2}$ to form a structurally characterized N-alkylformimidoyl complex. Organometallics 1983, 2, 1252-1254. (b) Cotton, F. A.; Daniels, L. M.; Matonic, J. H.; Wang, X.; Murillo, C. A. Metal-assisted unorthodox reactions of formamidines: coupling, cleavage and insertions. Polyhedron 1997, 16, 1177-1191. (c) Zhang, J.; Yi, W.; Zhang, Z.; Chen, Z.; Zhou, X. Facile Synthesis of Organolanthanide Hydrides with Metallic Potassium: Crystal Structures and Reactivity. Organometallics 2011, 30, 4320-4324.

28. Pyykkö, P.; Atsumi, M. Molecular Double-Bond Covalent Radii for Elements LiE112. Chem. Eur. J. 2009, 15, 12770-12779.

29. Cordero, B.; Gómez, V.; Platero-Prats, A. E.; Revés, M.; Echevarría, J.; Cremades, E.; Barragán, F.; Alvarez, S. Covalent Radii Revisited. Dalton Trans. 2008, 28322838 .

30. Cabon, N.; Pétillon, F. Y.; Orain, P. Y.; Schollhammer, P.; Talarmin, J.; Muir, K. W. Controlled nucleophilic activation of different sites in $\left[\mathrm{Mo}_{2} \mathrm{Cp}_{2} \mathrm{~L}_{2}(\mu-\mathrm{SMe})_{2}(\mu-\right.$ $\left.\left.\mathrm{L}^{\prime}\right)\right]^{+}$cations $\left(\mathrm{L}=\mathrm{Bu}^{\mathrm{t}} \mathrm{NC}\right.$, xylNC, $\mathrm{CO} ; \mathrm{L}^{\prime}=\mathrm{SMe}$ or $\left.\mathrm{PPh}_{2}\right)$. J. Organomet. Chem. 2005, 690, 4583-4601.

31. Alvarez, M. A.; Casado-Ruano, M.; García, M. E.; García-Vivó, D.; Ruiz, M. A. Structural and Chemical Effects of the $\mathrm{P}^{\mathrm{t}} \mathrm{Bu}_{2}$ Bridge at Unsaturated Dimolybdenum Complexes Having Hydride and Hydrocarbyl Ligands. Inorg. Chem. 2017, 56, 11336-11351.

32. Fischer, H.; Hoffmann, P.; Kreissl, F. R.; Schrock, R. R.; Schubert, U.; Weiss, K. Carbyne Complexes; VCH: Weinheim, Germany, 1988. 
33. (a) Pombeiro, A. J. L.; Guedes da Silva, M. F. C.; Michelin, R. A. Aminocarbyne complexes derived from isocyanides activated towards electrophilic addition. Coord. Chem. Rev. 2001, 218, 43-74. (b) Adams, R. D.; Babin, J. E.; Kim, H. S. The structure, bonding and transformation behaviour of iminium, aminocarbene and aminocarbyne ligands in triosmium cluster complexes. Polyhedron 1988, 7, 967-978.

34. (a) Prest, D. W.; Mays, M. J.; Raithby, P. R. The reactivity of the unsaturated dimeric rhenium complexes $\left[\mathrm{Re}_{2} \mathrm{H}_{2}(\mathrm{CO})_{6}\left\{(\mathrm{EtO})_{2} \mathrm{POP}(\mathrm{OEt})_{2}\right\}\right]$ and [Re $\left.\mathrm{Re}_{2} \mathrm{H}_{2}(\mathrm{CO})_{6}\left(\mathrm{Ph}_{2} \mathrm{PCH}_{2} \mathrm{PPh}_{2}\right)\right]: \quad X$-ray crystal structure of $\left[\mathrm{Re}_{2} \mathrm{H}(\mathrm{CO})_{6}\left(\mathrm{Ph}_{2} \mathrm{PCH}_{2} \mathrm{PPh}_{2}\right)\{\mu-\mathrm{NC}(\mathrm{H}) \mathrm{Me}\}\right]$. J. Chem. Soc., Dalton Trans. 1982, 2021-2028. (b) García-Alonso, F. J.; García-Sanz, M.; Riera, V.; Anillo-Abril, A.; Tiripicchio, A.; Ugozzoli, F. Reactions of Unsaturated Dihydrido Carbonyl Complexes of Manganese(I) with Nitriles and Isonitriles. Preparation and Characterization of the First Binuclear $\mu, \eta^{1}, \eta^{2}$-NCR Derivatives. Organometallics 1992, 11, 801-808. (c) Cabon, N.; Pétillon, F. Y.; Schollhammer, P.; Talarmin, J.; Muir, K. W. Reaction of $\mathrm{BH}_{4}^{-}$with $\left\{\mathrm{Mo}_{2} \mathrm{Cp}_{2}(\mu-\mathrm{SMe})_{n}\right\}$ species to give tetrahydroborato, hydrido or dimetallaborane compounds: control of product by ancillary ligands. Dalton Trans. 2004, 2708-2719.

35. (a) Cramer, C. J. Essentials of Computational Chemistry, 2nd Ed.; Wiley: Chichester, UK, 2004. (b) Koch, W.; Holthausen, M. C. A Chemist's Guide to Density Functional Theory, 2nd Ed.; Wiley-VCH: Weinheim, 2002.

36. (a) Calvert, R. B.; Shapley, J. R. Synthesis and Characterization of $\mathrm{HOs}_{3}(\mathrm{CO})_{10}\left(\mathrm{CH}_{3}\right), \mathrm{H}_{2} \mathrm{Os}_{3}(\mathrm{CO})_{10}\left(\mathrm{CH}_{2}\right)$, and $\mathrm{H}_{3} \mathrm{Os}_{3}(\mathrm{CO})_{10}(\mathrm{CH})$. Interconversion of Cluster-Bound Methyl and Methylene Ligands. J. Am. Chem. Soc. 1977, 99, 52255226. (b) Calvert, R. B.; Shapley, J. R. $\mathrm{HOs}_{3}(\mathrm{CO})_{10}\left(\mathrm{CH}_{3}\right)$ : NMR Evidence for a C.H.O. Interaction. J. Am. Chem. Soc. 1978, 100, 7726-7727. (c) Burgess, K.; Johnson, B. F. G.; Lewis, J.; Raithby, P. R. Reactions of $\left[\mathrm{Os}_{3}(\mu-\mathrm{H})_{2}(\mathrm{CO})_{10}\right]$ with diazo-compounds: structural characterization of $\left[\mathrm{Os}_{3}(\mu-\mathrm{H})(\mathrm{CO})_{10}\left(\mu-\mathrm{NHNCPh}_{2}\right)\right]$ and $\left[\mathrm{Os}_{3}(\mu-\mathrm{H})(\mathrm{CO})_{10}(\mu-\mathrm{NHNCPhMe})\right]$. J. Chem. Soc., Dalton Trans. 1982, $263-$ 269. (d) Koike, M.; Vander Velde, D. G.; Shapley, J. R. Solution Structure and Dynamics of $(\mu-\mathrm{H}) \mathrm{Os}_{3}(\mathrm{CO})_{10}\left(\mu-\mathrm{CH}_{3}\right)$. New ${ }^{1} \mathrm{H}$ and ${ }^{13} \mathrm{C}$ NMR Studies. Organometallics 1994, 13, 1404-1410.

37. (a) Carlucci, L.; Ciani, G.; v. Gudenberg, D. W.; D’Alfonso, G. Insertion reactions of diazoalkanes into a $\mathrm{Re}-\mathrm{H}-\mathrm{Re}$ bridge of $\left[\operatorname{Re}_{2}(\mu-\mathrm{H})_{2}(\mathrm{CO})_{8}\right]$. Synthesis and characterization of $\left[\operatorname{Re}_{2}(\mu-\mathrm{H})(\mathrm{CO})_{8}\left(\mu-\eta^{1}-\mathrm{N}(\mathrm{H}) \mathrm{NCPh}_{2}\right)\right]$ and of $\left[\operatorname{Re}_{2}(\mu-\mathrm{H})(\mathrm{CO})_{8}(\mu-\right.$ $\left.\left.\eta^{2}-\mathrm{CH}_{2} \mathrm{CO}_{2} \mathrm{Et}\right)\right]$. J. Organomet. Chem. 1997, 534, 233-235. (b) Carlucci, L.;

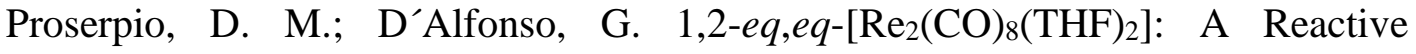


$\mathrm{Re}_{2}(\mathrm{CO})_{8}$ Fragment that Easily Activates $\mathrm{H}-\mathrm{H}$ and $\mathrm{C}-\mathrm{H}$ Bonds. Organometallics 1999, 18, 2091-2098.

38. García, M. E.; Ramos, A.; Ruiz, M. A.; Lanfranchi, M.; Marchiò, L. Structure and Bonding in the Unsaturated Hydride- and Hydrocarbyl-Bridged Complexes $\left[\mathrm{Mo}_{2}\left(\eta^{5}-\mathrm{C}_{5} \mathrm{H}_{5}\right)_{2}(\mu-\mathrm{X})\left(\mu-\mathrm{PCy}_{2}\right)(\mathrm{CO})_{2}\right]\left(\mathrm{X}=\mathrm{H}, \mathrm{CH}_{3}, \mathrm{CH}_{2} \mathrm{Ph}, \mathrm{Ph}\right)$. Evidence for the presence of $\alpha$-Agostic and $\pi$-Bonding Interactions. Organometallics 2007, 26, 6197-6212, and references therein.

39. By assuming a value of $130 \mathrm{~Hz}$ for the $\mathrm{C}-\mathrm{H}$ coupling in a regular bond, then the averaged figure of $113 \mathrm{~Hz}$ implies a value of $79 \mathrm{~Hz}$ for the $\mathrm{C}-\mathrm{H}$ coupling in the agostic bond of $\mathbf{8}$, in the low extreme of the usual range of $75-100 \mathrm{~Hz}$ for agostic bonds. See M. Brookhart, M. L. H. Green, J. Organomet. Chem. 1983, 250, 395408.

40. Churchill, M. R.; Wasserman, H. J. Structural Studies on Polynuclear Osmium Carbonyl Hydrides. 18. ${ }^{1,2}$ Molecular Geometry of $(\mu-\mathrm{H}) \mathrm{Os}_{3}(\mathrm{CO})_{10}\left(\mu-\mathrm{NHN}=\mathrm{CPh}_{2}\right)$. Inorg. Chem. 1981, 20, 2905-2909.

41. Schollhammer, P.; Guénin, E.; Pétillon, F. Y.; Talarmin, J. $\eta^{1}-\eta^{2}$ Rearrangement and Protonation of Phenyldiazo Bridging Ligands Attached to the Dimolybdenum System $\left\{\mathrm{Mo}_{2} \mathrm{Cp}_{2}(\mu \text {-SMe })_{3}\right\}$. Organometallics 1998, 17, 1922-1924.

42. Churchill, M. R.; Wasserman, H. J. Structural Studies on Polynuclear Osmium Carbonyl Hydrides. 17. $(\mu-\mathrm{H}) \mathrm{Os}_{3}(\mathrm{CO})_{10}[\mu-\mathrm{N}=\mathrm{N}(p$-tol $)]$. Inorg. Chem. 1981, 20, 1580-1584.

43. The related $\mathrm{Br}$ - and $\mathrm{Cl}$-bridged complexes display ${ }^{31} \mathrm{P} \mathrm{NMR}$ resonances in $\mathrm{CD}_{2} \mathrm{Cl}_{2}$ solution at $140.7 \mathrm{ppm}\left(J_{\mathrm{PW}}=375 \mathrm{~Hz}\right)$ and $137.4 \mathrm{ppm}\left(J_{\mathrm{PW}}=382 \mathrm{~Hz}\right)$, respectively. Toyos, A.; Ruiz, M. A. Unpublished results.

44. Verkade, J. G.; Mosbo, J. A. in Phosphorus-31 NMR Spectroscopy in Stereochemical Analysis; Verkade, J. G., Quin, L. D., Eds.; VCH: Deerfield Beach, FL, 1987; Chapter 13.

45. Armarego, W. L. F.; Chai, C. Purification of Laboratory Chemicals, 7th ed.; Butterworth-Heinemann: Oxford, U. K, 2012.

46. Vogel, A. I. Textbook of Practical Organic Chemistry, 4th ed.; Longmans: London, U. K., 1978, p 291.

47. APEX 2, version 2.0-1, Bruker AXS Inc: Madison, WI, 2005.

48. SMART \& SAINT Software Reference Manuals, Version 5.051; Bruker AXS Inc: Madison WI, 1998.

49. Sheldrick, G. M. SADABS, Program for Empirical Absorption Correction; University of Göttingen: Göttingen, Germany, 1996.

50. Farrugia, L. J. WinGX suite for small-molecule single-crystal crystallography. $J$. Appl. Crystallogr. 1999, 32, 837-838. 
51. (a) Sheldrick, G. M. A short history of SHELX. Acta Crystallogr., Sect. A 2008, 64, 112-122. (b) Sheldrick, G. M. Crystal structure refinement with SHELXL. Acta Crystallogr., Sect. C 2015, 71, 5-8.

52. CrysAlis Pro; Oxford Diffraction Limited, Ltd.: Oxford, U. K., 2006.

53. Frisch, M. J.; Trucks, G. W.; Schlegel, H. B.; Scuseria, G. E.; Robb, M. A.; Cheeseman, J. R.; Montgomery, Jr., J. A.; Vreven, T.; Kudin, K. N.; Burant, J. C.; Millam, J. M.; Iyengar, S. S.; Tomasi, J.; Barone, V.; Mennucci, B.; Cossi, M.; Scalmani, G.; Rega, N.; Petersson, G. A.; Nakatsuji, H.; Hada, M.; Ehara, M.; Toyota, K.; Fukuda, R.; Hasegawa, J.; Ishida, M.; Nakajima, T.; Honda, Y.; Kitao, O.; Nakai, H.; Klene, M.; Li, X.; Knox, J. E.; Hratchian, H. P.; Cross, J. B.; Bakken, V.; Adamo, C.; Jaramillo, J.; Gomperts, R.; Stratmann, R. E.; Yazyev, O.; Austin, A. J.; Cammi, R.; Pomelli, C.; Ochterski, J. W.; Ayala, P. Y.; Morokuma, K.; Voth, G. A.; Salvador, P.; Dannenberg, J. J.; Zakrzewski, V. G.; Dapprich, S.; Daniels, A. D.; Strain, M. C.; Farkas, O.; Malick, D. K.; Rabuck, A. D.; Raghavachari, K.; Foresman, J. B.; Ortiz, J. V.; Cui, Q.; Baboul, A. G.; Clifford, S.; Cioslowski, J.; Stefanov, B. B.; Liu, G.; Liashenko, A.; Piskorz, P.; Komaromi, I.; Martin, R. L.; Fox, D. J.; Keith, T.; Al-Laham, M. A.; Peng, C. Y.; Nanayakkara, A.; Challacombe, M.; Gill, P. M. W.; Johnson, B.; Chen, W.; Wong, M. W.; Gonzalez, C.; and Pople, J. A.; Gaussian 03, Revision B.02; Gaussian, Inc.: Wallingford, CT, 2004.

54. Becke, A. D. Density-functional thermochemistry. III. The role of exact exchange. J. Chem. Phys. 1993, 98, 5648-5652.

55. Lee, C.; Yang, W.; Parr, R. G. Development of the Colle-Salvetti correlationenergy formula into a functional of the electron density. Phys. Rev. B 1988, 37, 785-789.

56. Hay, P. J.; Wadt, W. R. Ab initio effective core potentials for molecular calculations. Potentials for potassium to gold including the outermost core orbitals. J. Chem. Phys. 1985, 82, 299-310.

57. (a) Hariharan, P. C.; Pople, J. A. Influence of polarization functions on MO hydrogenation energies. Theor. Chim. Acta 1973, 28, 213-222. (b) Petersson, G. A.; Al-Laham, M. A. A complete basis set model chemistry. II. Open-shell systems and the total energies of the first-row atoms. J. Chem. Phys. 1991, 94, 6081-6090. (c) Petersson, G. A.; Bennett, A.; Tensfeldt, T. G.; Al-Laham, M. A.; Shirley, W. A.; Mantzaris, J. A complete basis set model chemistry. I. The total energies of closedshell atoms and hydrides of the first-row elements. J. Chem. Phys. 1988, 89, 2193 2218. 
58. Wolinski, K.; Hinton, J. F.; Pulay, P. Efficient implementation of the gaugeindependent atomic orbital method for NMR chemical shift calculations. J. Am. Chem. Soc. 1990, 112, 8251.

59. Kutzelnigg, W.; Fleischer, U.; Schindler, M. The IGLO-Method: Ab-initio Calculation and Interpretation of NMR Chemical Shifts and Magnetic Susceptibilities. NMR: Basic Princ. Progr. 1990, 23, 165-262.

60. Portmann, S.; Luthi, H. P. MOLEKEL: An Interactive Molecular Graphics Tool. CHIMIA 2000, 54, 766-770. 


\section{(For Table of Contents Use Only)}

\section{Table of Contents Synopsis}

Different $p$-block element (E) molecules having $\mathrm{E}-\mathrm{H}$ bonds, or $\mathrm{C}-\mathrm{N}$ multiple bonds, readily add to the title complex under mild conditions, but this is invariably followed by additional processes, these including $\mathrm{E}-\mathrm{H}$ bond cleavage, dehydrogenation, insertion and denitrogenation, to give a plethora of derivatives having different ligands bridging the tungsten atoms.

\section{Graphics for Table of Contents}

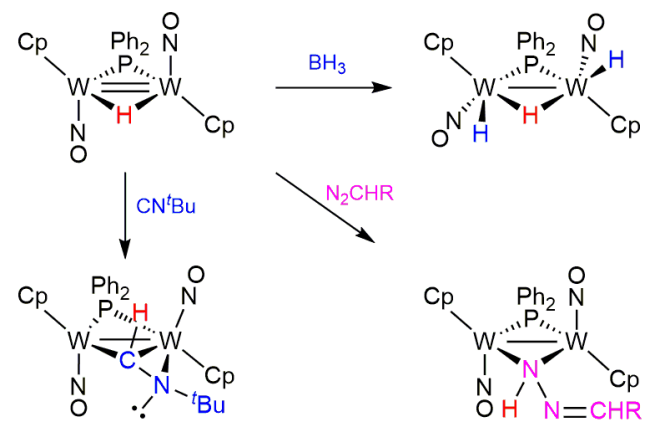

